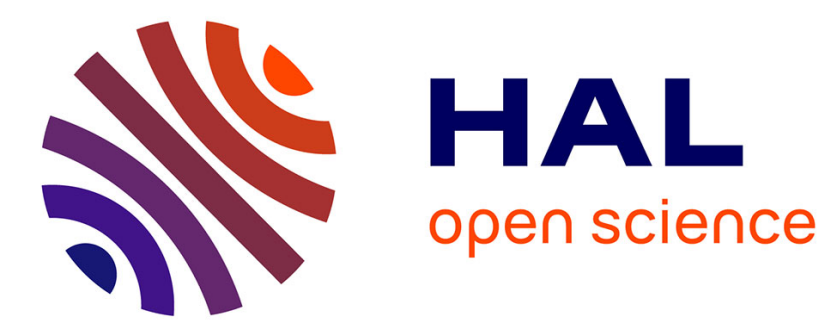

\title{
Stress release-induced interfacial twin boundary $\omega$ phase formation in a $\beta$ type Ti-based single crystal displaying stress-induced $\alpha "$ martensitic transformation
} Y. Yang, P. Castany, E. Bertrand, M. Cornen, J.X. Lin, T. Gloriant

\section{- To cite this version:}

Y. Yang, P. Castany, E. Bertrand, M. Cornen, J.X. Lin, et al.. Stress release-induced interfacial twin boundary $\omega$ phase formation in a $\beta$ type Ti-based single crystal displaying stress-induced $\alpha$ " martensitic transformation. Acta Materialia, 2018, 149, pp.97-107. 10.1016/j.actamat.2018.02.036 . hal-01740146

HAL Id: hal-01740146

https://hal-univ-rennes1.archives-ouvertes.fr/hal-01740146

Submitted on 6 Jul 2018

HAL is a multi-disciplinary open access archive for the deposit and dissemination of scientific research documents, whether they are published or not. The documents may come from teaching and research institutions in France or abroad, or from public or private research centers.
L'archive ouverte pluridisciplinaire HAL, est destinée au dépôt et à la diffusion de documents scientifiques de niveau recherche, publiés ou non, émanant des établissements d'enseignement et de recherche français ou étrangers, des laboratoires publics ou privés. 

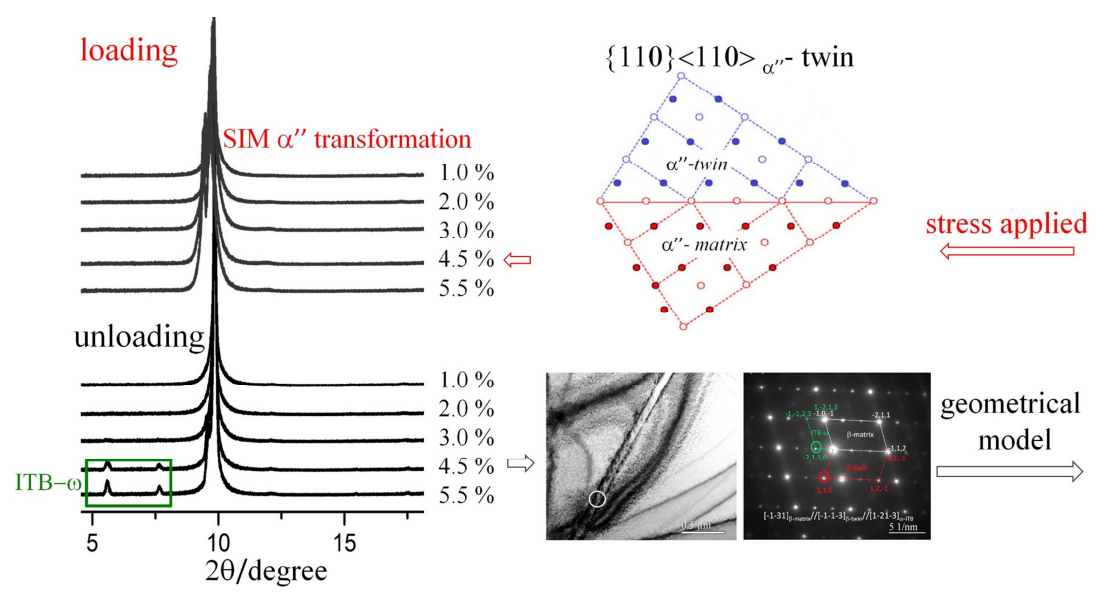

$\{112\}<111>_{\beta}$ twin + ITB- $\omega$

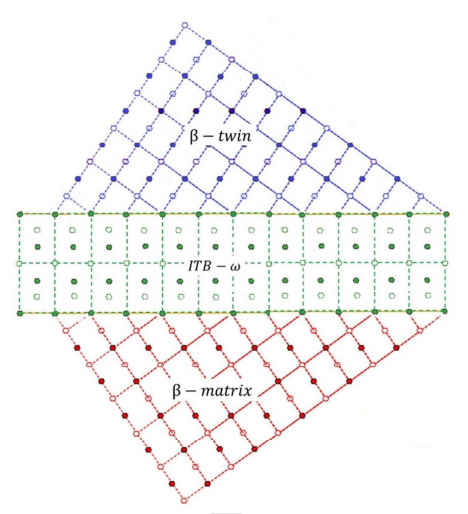




\section{Stress release-induced interfacial twin boundary $\omega$ phase formation in} a $\beta$ type Ti-based single crystal displaying stress-induced $\alpha$ " martensitic transformation

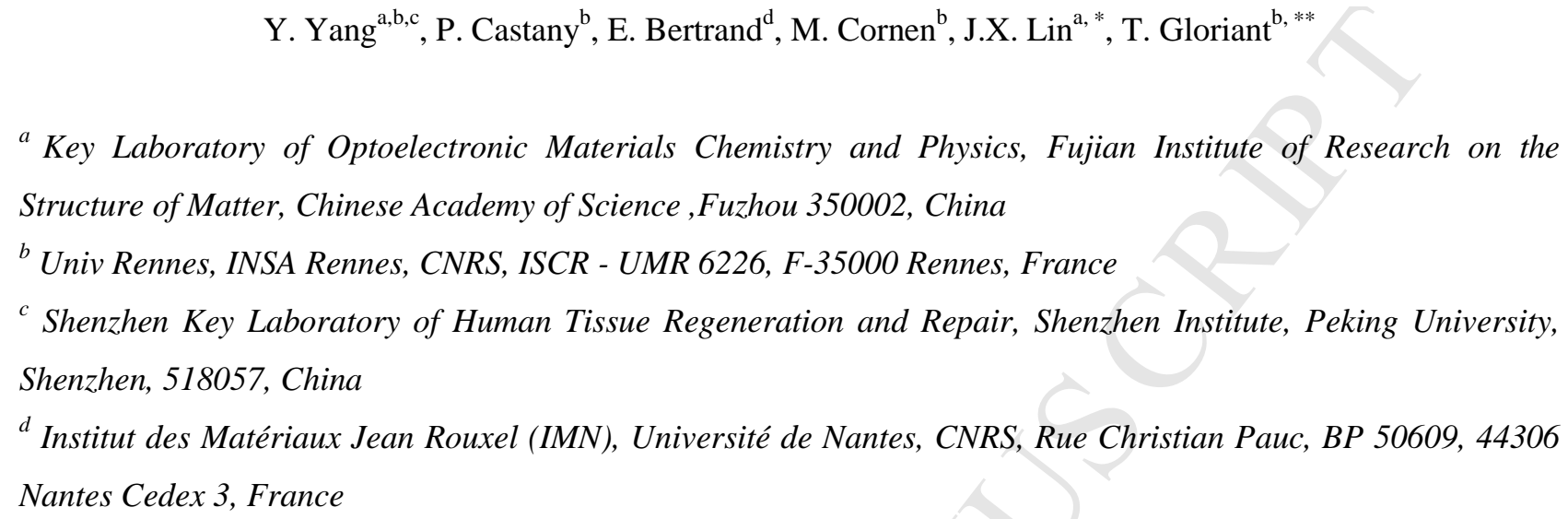

\section{Abstract}

The $\omega$ phase transformation in numerous group IV transition metals plays a key role to change the phase stability and modify mechanical properties, although its formation mechanisms and effect to accommodate strains are still unclear. $A<1 \quad 10\rangle_{\beta}$ single crystal of $\beta$-type Ti-24Nb-4Zr-8Sn alloy (wt. \%) is used to investigate the aforementioned problems. This alloy displays a $\beta$ to $\alpha$ " stress-induced martensitic transformation, which is reversible and leads to superelasticity. Profiles obtained from in situ synchrotron X-ray diffraction during cyclic tensile tests reveal definitely the appearance of $\omega$ phase due to applied stress releasing after unloading while these identified $\omega$ peaks shall vanish totally on subsequent loading. TEM microstructural observations show its morphology as thin layer locating on the boundary of $\left\{\begin{array}{lll}1 & 1 & 2\end{array}\right\}<1 \begin{array}{lll}1 & 1\end{array}>_{\beta}$ twins coinciding well with the feature of interfacial twin boundary (ITB) $\omega$ phase, which is proved to be formed passively during the

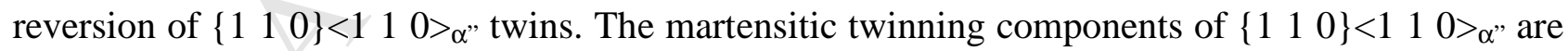
indeed confirmed from crystallographic reconstructions based on the orientation relationship between the $\beta$ and $\alpha$ " phases. A geometrical model is hence schematically used to analyze in details the orientation relationships between both deformation $\left\{\begin{array}{lll}1 & 1 & 2\end{array}\right\}<1 \quad 1 \quad 1>_{\beta}$ twins and ITB- $\omega$ phase, as well as with the original $\left.\left\{\begin{array}{lllllll}1 & 1 & 0\end{array}\right\}<\begin{array}{lll}1 & 0\end{array}\right\rangle_{\alpha \text { " twinning. }}$

Keywords: ITB- $\omega$ phase, deformation twinning, $\left.\left.\left\{\begin{array}{lll}1 & 1 & 2\end{array}\right\}<\begin{array}{lll}1 & 1 & 1\end{array}\right\rangle_{\beta},\left\{\begin{array}{lll}1 & 1 & 0\end{array}\right\}<\begin{array}{lll}1 & 1 & 0\end{array}\right\rangle_{\alpha \prime,}$, interfacial

${ }^{*}$ Corresponding author. E-mail address: franklin@ fjirsm.ac.cn (J.X. Lin)

** Corresponding author. E-mail addresses: thierry.gloriant@insa-rennes.fr (T. Gloriant) 


\section{Introduction}

Metastable $\beta$-type titanium based alloys are currently developed for applications in medicine and aerospace. Phase transformations from the body-centered cubic $\beta$ phase $\left(\mathrm{Im}-3 \mathrm{~m}, \mathrm{~N}^{0} 229\right)$ to base-centered orthorhombic $\alpha$ " phase $\left(\mathrm{Cmcm}, \mathrm{N}^{\mathrm{o}} 63\right)$ and hexagonal $\omega$ phase $\left(\mathrm{P} 6 / \mathrm{mmm}, \mathrm{N}^{\mathrm{o}} 191\right)$ are observed to be formed leading to several particular properties, such as superelasticity and shape memory effect. Although the stress-induced $\alpha$ " phase transformation from $\beta$ phase has been widely studied with the classic theory of martensitic crystallography (PTMC) [1-3], the role of $\omega$ phase was not clearly established. Especially, the importance of $\omega$ phase to accommodate internal strains in alloys, its effect on martensitic $\alpha$ " phase transformation and the role as precursor for stable $\alpha$ phase are still in debates.

As brittle particles known to be deleterious on mechanical properties, the isothermal $\omega$ phase was firstly identified in aged Ti-Cr alloy [4]. Various external stimulation including rapid cooling from single $\beta$ phase field in high temperature range, mechanical deformation, extremely high pressure and exposure to radiation were then claimed to enable the inducement of the $\omega$ phase in numerous group IV transition metals ( $\mathrm{Ti}$, Ta, Hf and $\mathrm{Zr}$ ) based alloys [5-9]. Depending on different historical processes, the particle morphologies of $\omega$ phase can be ellipsoidal or cuboidal after ageing [10-12] and plate-like in strained titanium alloys [13-15]. These morphological differences for $\omega$ phase can be attributed to both compositional partition and stressing condition [10-12, 16-18]. However, the model of collapsing one pair of $\left\{\begin{array}{llll}1 & 1 & 1\end{array}\right\}_{\beta}$ planes to an intermediate position leaving the adjacent $\left\{\begin{array}{lll}1 & 1 & 1\end{array}\right\}_{\beta}$ planes unaltered were proved and widely accepted as the formation mechanism of $\omega$ phase for nearly all cases $[3,19,20]$. Amongst them, thin layer $\omega$ phase located along the twin boundary, which was called ITB- $\omega$ [18], deserves more investigation. The two twinning systems observed in $\beta$-type Ti alloys are $\left\{\begin{array}{llllll}1 & 1 & 2\end{array}\right\}<\begin{array}{lll}1 & 1 & 1\end{array}>_{\beta}\left[\begin{array}{llll}18, & 19,21-25\end{array}\right]$ and $\left\{\begin{array}{lll}3 & 3 & 2\end{array}\right\}<1 \quad 13>_{\beta}$ [26-31]. In a recent work carried out in a Ti-Nb alloy [18], the formation of ITB- $\omega$ was observed due to a collapsing process of the $\left\{\begin{array}{llll}3 & 3 & 2\end{array}\right\}_{\beta}$ twin planes. The formation of such ITB- $\omega$ phase along $\left\{\begin{array}{lll}3 & 3 & 2\end{array}\right\}$ $<113>_{\beta}$ twins was also shown to be intrinsically due to the reverse $\alpha$ " to $\beta$ transformation and the subsequent stress relaxation along twin boundaries.

Such kind of ITB- $\omega$ phase was also observed in the vicinity of the $\left\{\begin{array}{llllll}1 & 1 & 2\end{array}\right\}<1 \quad 1 \quad 1>_{\beta}$ twin boundaries in a deformed Ti-15Mo-5Zr (at. \%) alloy [32]. Further, $\omega$-phase with a zigzag morphology was observed in a Ti-34Nb (at. \%) alloy and its formation was proposed to be featured 
by three-layer lattice shears arising from the dissociation and cross-slip of screw dislocations on consecutive $\left\{\begin{array}{lll}1 & 1 & 2\end{array}\right\}_{\beta}$ planes [23]. A detailed dislocation mechanism using the dissociation of the core of $1 / 2<1 \quad 1 \quad 1>_{\beta}$ dislocations into three $1 / 6<1 \quad 1 \quad 1>_{\beta}$ twinning dislocations and $1 / 12<1 \quad 1 \quad 1>_{\beta}$, $\begin{array}{lllll}1 / 3 & <1 & 1 & 1\end{array}>_{\beta}$ and $1 / 12<1 \quad 1 \quad 1>_{\beta}$ transition dislocations was described for interpretation of the mentioned boundary complexions [21]. Another mechanism was proposed from first principle calculations coupling with microstructural observations in the Ti-30Nb-3Pd (at. \%) alloy: The nucleation and growth of $\left\{\begin{array}{lll}1 & 1 & 2\end{array}\right\}<1 \quad 1 \quad 1>_{\beta}$ twins can be described on the basis of the reverse transformation of $\omega$ phase into $\beta$ phase [24, 33]. With such a mechanism, $\left.\left\{\begin{array}{lll}1 & 1 & 2\end{array}\right\}<1 \quad 1 \quad 1\right\rangle_{\beta}$ twins are formed inside $\omega$ particles and the ITB- $\omega$ phase observed along twin boundaries are the untransformed part of $\omega$ particles involved in the twinning process. The formation of ITB- $\omega$ phase along $\left\{\begin{array}{lll}1 & 1 & 2\end{array}\right\}<1 \quad 1 \quad 1>_{\beta}$ twin boundaries is thus mainly describe from mechanisms which do not consider the $\beta-\alpha$ " transformation. But the comprehensive participation of martensitic $\alpha$ " transformation and $\left\{\begin{array}{lll}1 & 1 & 2\end{array}\right\}<1 \begin{array}{lll}1 & 1\end{array}>_{\beta}$ deformation twins on the formation mechanism for the ITB- $\omega$ phase is of great interest and a deeper understanding on the formation sequence or mediation details have never been reported.

In the present work, a $\beta$-type titanium based alloy with the chemical composition of Ti-24Nb-4Zr-7.9Sn (wt. \%, short for Ti2448 thereafter) was investigated. This Ti2448 alloy was firstly designed for biomedical implants and prostheses because it exhibits a Young's modulus as low as $42 \mathrm{GPa}$ and a superelastic behavior characterized by a maximum recoverable strain of $3.3 \%$ [25, 34-39]. As the origin of superelasticity, the stress-induced $\alpha$ " martensitic transformation was evidenced in polycrystalline deformed specimens [37]. In the present case, a $\left\langle\begin{array}{lll}1 & 0 & 0\end{array}\right\rangle_{\beta}$ single crystal of this Ti2448 alloy was elaborated to simplify the microstructure. In situ synchrotron X-ray diffraction (SXRD) under cyclic tensile test were used to detect the stress-induced martensitic $\alpha$ " phase transformation and ITB- $\omega$ phase formation. Further TEM and orientation analysis were performed to reveal the transformation details. A new deformation sequence for deformation $\beta$ twinning and ITB- $\omega$ formation, as well as the relevant geometrical model indicating the change of the crystallographic lattice were finally obtained.

\section{Materials and methods}

Ingot of Ti-24Nb-4Zr-8Sn (wt. \%) alloy with diameter of $55 \mathrm{~mm}$ was made by arc melting under argon and hot forged at $1273 \mathrm{~K}$ into $25 \mathrm{~mm}$ diameter bar. A cylinder of $8.6 \mathrm{~mm}$ in diameter was cut from the as-forged bar and used to grow seed-crystal rods in an optical floating-zone furnace (FZ-T-12000-X-VP-S, Crystal System Inc.) under the protection of flowing argon. The growth was 
carried out at a rate of $5 \mathrm{~mm} \cdot \mathrm{h}^{-1}$ and a rotation rate of $25 \mathrm{rpm}$. The seed crystal was cut along the $<110\rangle_{\beta}$ direction after the orientation was determined by both X-ray diffraction (XRD) and Laue X-ray back reflection analyses within $1^{\circ}$ of the desired orientation and then used to grow single-crystal rods. The orientation of the grown single crystal was also confirmed by Laue X-ray back reflection analysis. XRD and transmission electron microscopy (TEM) were used to examine the single $\beta$ phase and confirm the absence of formation of both $\omega$ phase and $\alpha$ " martensitic phase. Chemical analyses showed that the grown crystals has a similar composition compared to the forged bar.

Cyclic tensile test at room temperature consisting of strain increments of $0.5 \%$ followed by stress release up to an elongation of $5.5 \%$ was conducted with an INSTRON 3369 tensile machine (strain rate: $10^{-4} \mathrm{~s}^{-1}$ ). An extensometer was used to ensure the accurate control of the strain. The tensile direction was chosen parallel to the single crystal growth direction, i.e. the $\left\langle 1 \quad 1 \quad 0>_{\beta}\right.$ direction. In order to observe the deformed microstructure, single crystal specimens were cut after tensile tests and prepared by mechanically grinding with increasing grades of $\mathrm{SiC}$ abrasive paper, then polished with colloidal silica suspension and finally etched in a solution composed of $8 \% \mathrm{HF}$, $15 \% \mathrm{HNO}_{3}$ and $77 \% \mathrm{H}_{2} \mathrm{O}$ (vol. \%). Further observations were conducted using a JEOL 2100 transmission electron microscope (TEM) operating at $200 \mathrm{kV}$. Thin foils for TEM observations were cut as disks of $3 \mathrm{~mm}$ in diameter, further polished to a thickness of $150 \mu \mathrm{m}$ and prepared by a twin-jet electro-polishing technique with a $6 \%$ perchloric acid and $94 \%$ methanol (vol. \%) solution at $-25{ }^{\circ} \mathrm{C}$. Twin-jet electro-polishing was stopped before perforation and the samples were finally thinned by ion milling with a Fischione 1010 Model.

In situ synchrotron X-ray diffraction (SXRD) under cyclic tensile test was conducted on beam line ID31 at the European Synchrotron Radiation Facility (ESRF, Grenoble, France) with a $5 \mathrm{kN}$ micro-tensile dispositive. The high-resolution ID31 beamline offers a high-energy incident X-ray beam $(\lambda=0.040002106 \mathrm{~nm})$ coupled with a nine-channel multi-analyzer installed as detectors. The transmitted diffracted beams were collected over the $\theta$ angular range $2-14^{\circ}$ with a scanning step of $0.005^{\circ}$. The in situ cyclic tensile tests under synchrotron radiation were realized on the same single crystal tensile specimen (gauge width of $3 \mathrm{~mm}$ and a thickness of $0.5 \mathrm{~mm}$ ) with increments of $0.5 \%$ until $5.5 \%$. SXRD scans were therefore obtained after each strain increment for both loading and unloading conditions. More details about the setup configuration can be found in reference [40]. 


\subsection{Tensile test}

Fig. 1 displays the cyclic tensile curve from 0 to $5.5 \%$ strain for the $\langle 110\rangle_{\beta}$ single crystal. On this curve, large hysteresis loops can be clearly observed due to the stress-induced martensitic transformation (SIM) occurring. Indeed, after the linear elasticity of the $\beta$ phase, a stress plateau can be noticed in the strain range of $0.75 \sim 3 \%$ which corresponds to the main stage of SIM $\alpha$ " transformation. Thus, the critical stress for the SIM $\alpha$ " transformation can be evaluated to be 250 $\mathrm{MPa}$ with the method of intersection point between two tangent lines. After $3 \%$ of strain, the martensitic $\alpha "$ phase begins to deform elastically followed by its plastic deformation. The recoverable strains used to evaluate the superelasticity at different applied strains are measured with the method illustrated in reference [41] and displayed with black open circles according to the right vertical axis. It can be noticed that the recoverable strain increases linearly with the applied strain up to $4 \%$ of strain. Up to this value, the applied strain can be totally recovered due to the reversibility of the SIM $\alpha$ " transformation. On the other hand, the incipient Young's modulus and the ultimate tensile strength are measured to be $51 \mathrm{GPa}$ and $623 \mathrm{MPa}$, respectively.

\subsection{In situ SXRD characterization}

Fig. 2a presents the whole SXRD profiles of the single crystal during the cyclic tensile test on loading (upper in red) and after unloading (lower in black) between 0 and $5.5 \%$ of applied strain. On the first initial profile, only $\left(\begin{array}{lll}1 & 1 & 0\end{array}\right)_{\beta}$ and $\left(\begin{array}{lll}2 & 2 & 0\end{array}\right)_{\beta}$ peaks are detected, which is in accordance with the $\left\langle 110>_{\beta}\right.$ single crystalline state. When the applied strain increases, SIM $\alpha$ " transformation occurs. However, the diffracted peaks belonging to $\alpha^{\prime \prime}$ phase are very close to the $\left\{\begin{array}{lll}1 & 1 & 0\end{array}\right\}_{\beta}$ and $\begin{cases}2 & 2\end{cases}$ $0\}_{\beta}$ peaks that is why three enlarged angle ranges from Fig. $2 \mathrm{a}$ are presented in Fig. 2b, 2c and $2 \mathrm{~d}$ for a better identification of the phase evolution.

In the Fig. $2 b$ that shows profiles on loading, it can be noticed that the $\left(\begin{array}{lll}1 & 1 & 0\end{array}\right)_{\beta}$ peak slightly shifts to the low angles due to the elastic expansion of the $\beta$ lattice until the detection of the $\left(\begin{array}{lll}0 & 20\end{array}\right)_{\alpha "}$ diffraction peak when the applied strain reaches $1 \%$. Then, the other typical diffraction peaks of

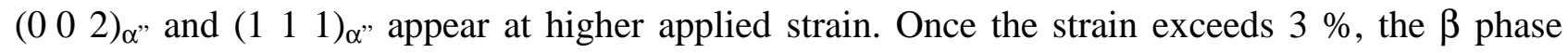
seems to disappear totally that will be confirmed hereafter from the calculation of transformation strains. This assumption is highlighted by the vanishing of $\left(\begin{array}{lll}1 & 1 & 0\end{array}\right)_{\beta}$ peak replaced by the superimposition of the three $\left(\begin{array}{llll}0 & 2 & 0\end{array}\right)_{\alpha ",},\left(\begin{array}{lll}0 & 0 & 2\end{array}\right)_{\alpha "}$, and $\left(\begin{array}{lll}1 & 1 & 1\end{array}\right)_{\alpha}$ " diffraction peaks. Under the 


\section{ACCEPTED MANUSCRIP'}

corresponding unloading conditions in Fig. $2 \mathrm{c}$, nearly all the diffraction peaks of the $\alpha$ " phase disappear while the peak of the $\beta$ phase appears back, showing the $\alpha$ " phase reverses back to its parent $\beta$ phase before the strain reaches $3.5 \%$. Positions of peaks of $\alpha$ " phase are also indicated, but the quantity of residual martensite is negligible for the $3.5 \%$ condition, while its presence is more obvious at higher strain, even if the $\beta$ phase is the main phase remaining after unloading. Moreover, the reversed $\left(\begin{array}{lll}1 & 1 & 0\end{array}\right)_{\beta}$ peak and remaining peaks of $\alpha$ " (when there are) keep in the same position, implying that the shift of all peaks observed on loading is due to the elasticity of the two phases. For profiles under the unloading condition released from a higher applied strains at $4.5 \sim 5.5 \%$ in Fig. 2c, diffraction peaks of $\left(\begin{array}{lll}0 & 0 & 2\end{array}\right)_{\alpha \prime \prime}$ and $\left(\begin{array}{lll}1 & 1 & 1\end{array}\right)_{\alpha^{\prime \prime}}$ with tiny intensity are left around the main $\left(\begin{array}{ll}1 & 1\end{array}\right.$ $0)_{\beta}$ peak. This is because the SIM $\alpha$ " transformation cannot be totally reversed due to the onset of plastic deformation which inhibits the reverse martensitic transformation.

Another interesting phenomenon can be noticed in Fig. 2d. Indeed, two small but well-identified peaks at $5.6^{\circ}$ and $7.6^{\circ}$ are clearly visible. However, they cannot be indexed from any $\alpha$ " or $\beta$ phases. In fact, these two peaks can be indexed as the $\left(\begin{array}{lllll}0 & 1 & -1 & 0\end{array}\right)_{\omega}$ and $\left(\begin{array}{llll}0 & 0 & 0 & 1\end{array}\right)_{\omega}$ planes of the $\omega$ phase, which is also a common observed phase in both deformed and quenched metastable Ti-based alloys. Such a formation of $\omega$ phase when the stress is released from the plastic deformation domain was never reported and the reason of its appearance will be explicated further from the microstructural analysis.

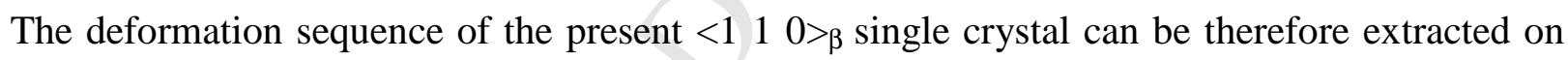
the basis of both the SXRD profiles and analysis of cyclic tensile curves in the Fig. 1. The deformation begins from pure elastic deformation of $\beta$ phase. At the $0.5 \%$ strain, the SIM $\alpha$ " starts to occur and continues to coexist with the elastic deformation of the $\beta$ phase until the fulfillment of the phase transformation at $3 \%$ strain. At the strain range of $3 \sim 4.5 \%$, the SIM $\alpha$ " phase deforms elasticity then stepped into a complete plastic deformation range of $4.5 \sim 5.5 \%$ characterized by the stabilization of permanent deformation. During this last step, an unexpected formation of $\omega$ phase after releasing the stress is also evidenced.

Evolutions of the cell parameters of $\beta$ and SIM $\alpha$ " phases are also determined from the diffraction profiles and are plotted in Fig. 3 as a function of the applied percentage strain under loading conditions. The lattice parameter of $\beta$ phase is continuously increasing when the strain increases until $3 \%$ strain on loading while keeps constant after unloading. For the SIM $\alpha$ " phase, the $b_{\alpha^{\prime \prime}}$ and $c_{\alpha^{\prime \prime}}$ parameters continuously increases when the strain increases while the $a_{\alpha \prime}$ parameter is roughly constant. It is also worth noting that lattice parameters of the $\alpha$ " phase cannot be properly determined for applied strain smaller than $3 \%$ due to a limited number of diffraction peaks 
although SIM $\alpha$ " transformation already occurs. The cell parameters of $\beta$ phase, SIM $\alpha$ " phase and $\omega$ phase, which are determined within the plastic deformation range after unloading, are presented in Table 1. These values are used to calculate the phase transformation strains for each possible variants of $\alpha^{\prime \prime}$ martensite (Table 2). As generally assumed, this is the variant leading to the maximum of transformation strain that would be formed, i.e. the CV3 here with a value of about $4.3 \%$. This means the recoverable strain would be measured as $4.3 \%$ if all the $\beta$ phase transforms into $\alpha$ " martensite with a full reversibility after unloading. As the maximum recoverable strain was indeed measured as $4.3 \%$ (Fig. 1), one can conclude that all the $\beta$ phase is transformed during deformation as assumed from the description of SXRD results (Fig. 2).

\subsection{Microstructural observations}

An example of the plastically deformed microstructure observed by optical microscopy for a sample deformed at $4.5 \%$ is presented in Fig. 4. Two groups of deformation bands crossed with each others can be clearly observed on this micrograph. In order to determine the nature of these bands, TEM observations were carried out.

Fig. 5 shows the TEM observations of the single crystal deformed at $4.5 \%$ strain. The bright field image (BFI) in Fig. 5a presents dislocation pile-ups indicating the involvement of dislocation slip. The selected area electron diffraction (SAED) of Fig. 5b corresponding to the circled area of the matrix in Fig. 5a was indexed as the $\beta$ phase with the $\left[\begin{array}{lll}1 & 1 & 3\end{array}\right]_{\beta}$ zone axis. A careful analysis of the slip trace on the Fig. 5a according to the crystallographic orientation of the single crystal shows the dislocations slip in a $\left\{\begin{array}{lll}1 & 1 & 0\end{array}\right\}_{\beta}$ plane (more details about the method can be found in reference [42]). This result is consistent with the most common slip planes observed in the $\beta$ phase of titanium alloys but also in other bcc alloys [43-45]. A BFI from another typical area is presented in Fig. 5c and its corresponding SAED in Fig. 5d. It can be seen the superimposition of three sets of diffraction patterns marked by different colors on the SAED. After indexation, the deformation

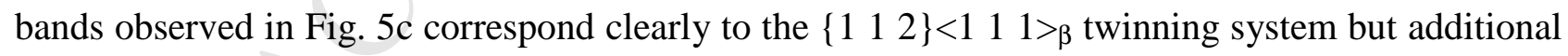
$\omega$ phase diffracted spots are also observed sharing the common zone axis for $\left[\begin{array}{lll}1 & 1 & 0\end{array}\right]_{\beta \text {-matrix }} / /\left[\begin{array}{lll}1 & 1\end{array}\right.$

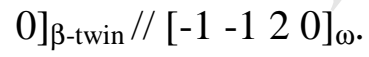

The TEM observations of another area in Fig. $6 \mathrm{a}$ and $6 \mathrm{~b}$ also confirms the formation of plastic $\left\{\begin{array}{lll}1 & 1 & 2\end{array}\right\}<1 \quad 1 \quad 1>_{\beta}$ twins and the formation of $\omega$ phase but with a different diffracting condition corresponding to $\left[\begin{array}{lll}-1 & -3 & 1\end{array}\right]_{\beta \text {-matrix }} / /\left[\begin{array}{lll}-1 & -1 & -3\end{array}\right]_{\beta-\text { twin }} / /\left[\begin{array}{llll}1 & -2 & 1 & -3\end{array}\right]_{\omega}$ zone axis. It can be noticed that, for this specific orientation, the common $\left\{\begin{array}{lll}1 & 1 & 2\end{array}\right\}$ plane between the twin and the matrix, which can be seen on the SAED pattern, is not the twinning plane. The twinning plane will be further indicated in 
the Fig. $7 \mathrm{a}$ and $7 \mathrm{~b}$. Diffracted spots related to the twin and $\omega$ phase are selected and relevant dark-field images are shown in Fig. $6 c$ and 6 d. It is worth noting that the $\omega$ phase shows a strong contrast, which allows to observe its localization at the twin boundary. This indicates its nature of interfacial twin boundary phase (ITB- $\omega$ ). The $\omega$ phase layer appears here rather thick because the twin interface is inclined according to the electron beam. Due to the crystallographic orientation of this twin, it was not possible to get the twin interface edge-on (see Fig. 7a and 7b). It can also be noticed that such an ITB $\omega$ phase exhibiting a thin layer morphology was already reported in other $\beta$-metastable titanium alloys $[16,18,19]$.

This ITB $\omega$ phase is thus the $\omega$ phase that is detected during the SXRD experiments, as no nano-sized athermal $\omega$ phase can be detected from SAED patterns. Indeed, no diffuse streaks are visible on the $[113]_{\beta}$ zone axis SAED pattern (Fig. 5b) as commonly observed when precipitation of athermal $\omega$ phase occurs during the quench $[3,10,13]$. Therefore, the $\omega$ phase detected by SXRD is not athermal $\omega$ phase initially present in the microstructure but is truly the ITB $\omega$ phase observed by TEM along the twin boundaries.

\section{Discussion}

We showed by SXRD analysis that the microstructure of samples after stress released from the plastic deformation range consists mainly of $\beta$ phase with a small amount of residual SIM $\alpha$ " phase and ITB- $\omega$ phase. However, the TEM observations on sample released from $4.5 \%$ do not exhibit any detection of SIM $\alpha$ " phase. The reason is due to internal stress relaxation occurring during the thin foil preparation, which is reasonably accepted. The point to elucidate now concerns the mechanism of the ITB- $\omega$ phase formation. Indeed, this phase is never observed when the sample is under stress but only when the sample is released after being deformed in the plastic domain according to our SXRD analyses. The problem is that many transformations occurred in this metastable alloy such as the stress-induced martensitic transformation, twinning and $\omega$-phase formation, which can be reversible and depend on each other.

The SIM $\alpha$ " transformation was confirmed by SXRD experiments with a phase-transformed fraction of $100 \%$ when a strain of $4.5 \%$ is reached. That means that the plastic deformation mechanisms, such as twining and dislocation slip, occur in this SIM $\alpha$ " phase and not in the $\beta$ phase. Indeed, the plastic deformation starts between 4 and $4.5 \%$ of applied strain, as some residual strain starts to be measured after unloading from $4.5 \%$ (Fig. 1). In addition, as the formation of $\omega$ phase is observed only after unloading from $4.5 \%$ of applied strain, that means the $\omega$ phase is formed after plastic deformation has occurred, and thus after twinning of martensite has occurred. It is also worth 


\section{ACCEPTED MANISCRIP}

noting that the $\omega$ phase is not detected after further loading (5\%) but appears again when the stress is removed again: The formation of $\omega$ phase is thus reversible, meaning that the observed twins in the $\beta$ phase with the ITB $\omega$ phase can transform again into twins in the $\alpha$ " martensite without any $\omega$ phase during subsequent loading. Plastic deformation mechanisms of $\alpha^{\prime \prime}$ martensite are not exhaustively known but twinning was already reported in the literature as the $\left\{\begin{array}{lll}1 & 3 & 0\end{array}\right\}\langle 3 \quad 1 \quad 0\rangle_{\alpha}$ " or the $\left.\left\{\begin{array}{lll}1 & 1 & 0\end{array}\right\}<\begin{array}{llll}1 & 1 & 0\end{array}\right\rangle_{\alpha}$, twinning systems [46-48]. Therefore, the observed $\left\{\begin{array}{lll}1 & 1 & 2\end{array}\right\}<1 \quad 1 \quad 1>_{\beta}$ twins combined with the stress release-induced ITB- $\omega$ phase formation is believed to be linked directly with the $\alpha$ " martensitic twinning under stress condition. In order to prove this hypothesis, the $\alpha$ " martensitic twinning components has to be detailed on the basis of the well-known orientation relationship (OR) between the body-centered cubic $\beta$ phase and the orthorhombic $\alpha$ " phase given in Table 2 [49]. These data are used to make the crystallographic reconstruction of $\alpha$ " twins on loading from the crystallographic orientations of the $\beta$ phase observed after the stress is removed.

By way of illustration, the crystallographic orientations of the $\beta$-matrix and $\beta$-twin observed in the Fig. 6 are presented on stereographic projections in Fig. $7 \mathrm{a}$ and $7 \mathrm{~b}$. The common $(-1-2-1)_{\beta}$ twinning plane is indicated as well as the common $<111>_{\beta}$ twinning direction. The corresponding crystallographic orientations of matrix and twin after transformation into $\alpha$ " phase were then determined by applying the OR. Actually, six possible orientations of $\alpha$ ", named variants (V1 to V6) were deduced from a certain orientation of $\beta$-matrix or $\beta$-twin. All the combinations between both orientations of matrix and twin were tested in order to identify a potential twinning relationship in the $\alpha$ " phase under stress condition. For that, a rotation of $180^{\circ}$ around the potential common twinning direction or reflection through the common twinning plane were made to confirm the twinning relationship. The tested potential common twinning planes and directions were referenced in several articles related to $\alpha$ " martensite or similar structure in $\alpha$-uranium [47, 50-52]. Finally, only one convincing possibility was found between the $\alpha$ "-matrix-V3, and $\alpha$ "-twin-V3, both represented in Fig. 7c and Fig. 7d, respectively. The twining relationship found here corresponds thus to a compound $\left.\left\{\begin{array}{lllllll}1 & 1 & 0\end{array}\right\}<1 \quad 10\right\rangle^{\prime \prime}$ twin.

It is demonstrated clearly that the $\alpha "$-matrix-V3 and $\alpha "$-twin-V3 keep a $\left.\left\{\begin{array}{llllllll}1 & 1 & 0\end{array}\right\}<\begin{array}{llll}1 & 0\end{array}\right\rangle^{\prime \prime}$ twinning relationship, because (i) the two projections share a common $\left(\begin{array}{lll}-1 & -1 & 0\end{array}\right)_{\alpha \text { " pole and a }}$ common $\left[\begin{array}{lll}-1 & 1 & 0\end{array}\right]_{\alpha,}$ direction indicated in Fig. $7 \mathrm{c}$ and $7 \mathrm{~d}$ and (ii) the operation of a reflection through

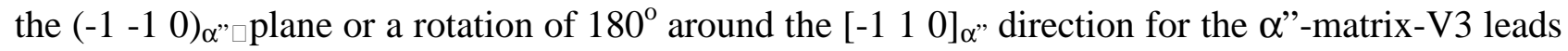
to the orientation of the $\alpha$ "-twin-V3. Therefore, the $\alpha$ "-matrix-V3 and $\alpha$ "-twin-V3 are in the

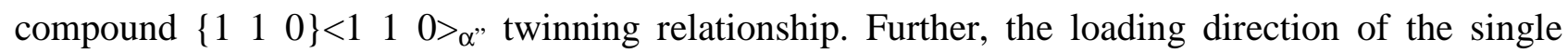

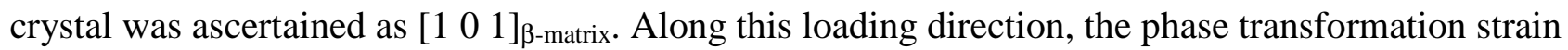


can be thus calculated according to theory of PTMC [53] and results were presented in Table 2. The maximum value is calculated as $4.29 \%$ for V3. As it is generally assumed that the variant that is formed during a tensile test is the one giving the maximum of transformation strain, the occurrence of V3 is then in good agreement with the orientation of the single crystal of $\beta$ phase. It can also be noticed that, according to the Fig. 1, the residual strain of approx. $0.2 \%$ is measured at the applied strain of $4.5 \%$ which is exactly the sum of phase transformation strain (4.29\%) and residual strain $(0.2 \%)$. Thus, the results of crystallographic reconstruction to determine the twinning system in $\alpha$ " martensite are in perfect accordance to the variant selection of $\alpha$ " due to the external stress.

Moreover, the twining plane $\left(\begin{array}{lll}-1 & -1 & 0\end{array}\right)_{\alpha^{\prime \prime}}$ and the twining direction $\left[\begin{array}{lll}-1 & 1 & 0\end{array}\right]_{\alpha^{\prime \prime}}$ indicated in Fig. 7c coincide exactly with the twining plane $(-1-2-1)_{\beta}$ and the twining direction $\left[\begin{array}{lll}1 & -1 & 1\end{array}\right]_{\beta}$ in Fig. 7a, respectively, indicating a clear lattice correspondence between the deduced $\left\{\begin{array}{llllll}1 & 1 & 0\end{array}\right\}\left\langle\begin{array}{llll}1 & 0 & \rangle_{\alpha} \text { " }\end{array}\right.$ twinning system in the $\alpha$ " phase and the observed $\left\{\begin{array}{lll}1 & 1 & 2\end{array}\right\}<1 \quad 1 \quad 1>_{\beta}$ twinning system in the relaxed $\beta$ phase. The crystallographic orientation of the ITB- $\omega$ phase obtained from the DP in Fig. $6 \mathrm{~b}$ is also shown with a stereographic projection in Fig. 7e. Some interfacial features can be found obviously:

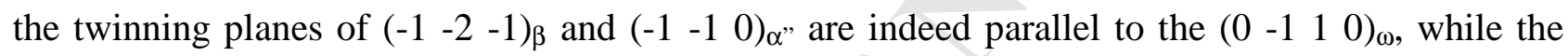
twinning directions of $\left[\begin{array}{lll}1 & -1 & 1\end{array}\right]_{\beta}$ and $\left[\begin{array}{lll}-1 & 1 & 0\end{array}\right]_{\alpha,}$, are parallel to the $\left[\begin{array}{llll}0 & 0 & 0 & -1\end{array}\right]_{\omega}$ of the ITB- $\omega$ phase. The present orientation relationship between $\beta$ and $\omega$ phase is specific for ITB- $\omega$ phase with a strong correlation between the twinning elements and the $\omega$ phase. Indeed, the twinning plane is parallel to $\left(\begin{array}{llll}0 & -1 & 1 & 0\end{array}\right)_{\omega}$ and the twinning direction is parallel to the $\left[\begin{array}{llll}0 & 0 & 0 & 1\end{array}\right]_{\omega}$ direction. This specific orientation relationship was already pointed out in a gum metal alloy for the same twinning system [16] and also in a Ti-Nb binary alloy for the $\left\{\begin{array}{llllll}3 & 3 & 2\end{array}\right\}<\begin{array}{llll}1 & 1 & 3\end{array}>_{\beta}$ twinning system [18], both exhibiting such ITB- $\omega$ phase. An explicit illustration of these orientation relationships is exhibited in Fig. $7 \mathrm{f}$ based on eighteen unit cells of $\beta$ phase highlighted with red color. The unit cell of $\alpha$ " phase and ITB- $\omega$ phase are then highlighted with blue and green colors, respectively. Moreover, the path for atoms displacements which are necessary to realize the phase transformation are marked by hollows atoms and corresponding arrows.

The release of applied strain from the plastically deformed single crystal causes the reverse martensitic transformation, thus the microstructure is observed as the resultant $\left\{\begin{array}{llllll}1 & 1 & 2\end{array}\right\}<1 \quad \begin{array}{lll}1 & 1\rangle_{\beta} \text { type }\end{array}$ with ITB- $\omega$ phase that is formed in order to minimize the surface energy of complex boundaries. As reported in a recent work [18], the ITB- $\omega$ phase is assumed to accommodate strains that are originated from the reverse martensitic transformation of the $\left.\left\{\begin{array}{lllll}1 & 3 & 0\end{array}\right\}<3 \quad 1 \quad 0\right\rangle_{\alpha}$, twin boundary into $\left\{\begin{array}{lll}3 & 3 & 2\end{array}\right\}<\begin{array}{lll}1 & 1 & 3\end{array}>_{\beta}$ twin interfaces in a metastable $\beta$-type Ti-Nb alloy. The ITB- $\omega$ phase formed in the

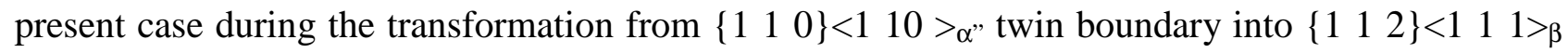




\section{ACCEPTFD MANUSCRTPT}

twin actually follows the similar mechanisms but is activated along different crystallographic planes and directions.

The geometrical models for the deformation twinning and ITB- $\omega$ phase are presented in Fig. 8 according to the lattice correspondence in Fig. 7f. The projection of the lattice is chosen to be along

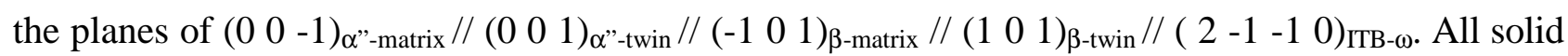
circles indicate the atoms in the plane of figure, while the open circles the atoms below the plane of figure. The red, blue and green atoms refer to the initial lattice, the twinned lattice and the resultant ITB- $\omega$ lattice, respectively. The Fig. 8a firstly illustrates $\left.\left\{\begin{array}{lll}1 & 1 & 0\end{array}\right\}<\begin{array}{llll}1 & 1 & 0\end{array}\right\rangle_{\alpha}$ twinning formed via plastic deformation on the basis of fully transformed $\alpha$ " matrix. The twinning plane $(-1-10)_{\alpha \text { "-matrix }}$ and twinning direction $\left[\begin{array}{lll}-1 & 1 & 0\end{array}\right]_{\alpha "-m a t r i x}$ are marked. It is worth noting, that the atomic layers A, B, C are not at equal distance to each other. The distance between these planes is dependent on the value of $y$, which is a parameter related to the positions of atoms in the orthorhombic cell of the $\alpha$ " phase. Its value lies between $1 / 6$ and $1 / 4$, while the value $y=1 / 6$ describes an hcp structure ( $\alpha$ phase) and the value $y=1 / 4$ describes a bcc structure $(\beta$ phase).

The observed $\left\{\begin{array}{lll}1 & 1 & 2\end{array}\right\}<1 \quad 1 \quad 1>_{\beta}$ twin and ITB- $\omega$ phase which are passively formed after releasing the stress are also presented in Fig.8b. It can be noticed that the reverse transformation from $\alpha "$ to $\beta$ leads to an equal distance between $\mathrm{A}, \mathrm{B}$ and $\mathrm{C}$ atomic layers. Moreover, these atomic layers are also equally distanced in the $\omega$ phase. So, the reverse transformation is helpful to form an ITB- $\omega$ phase during the phase rerversion. Some atoms have thus to be slightly moved to form the $\omega$ phase (arrows on the fig. 8b). The final configuration of the twin interface after removing the stress is then illustrated in the Fig.8c with the orientation relationship between the ITB- $\omega$ phase and both the twin and matrix of the $\beta$ phase which are in a $\left.\left\{\begin{array}{lll}1 & 1 & 2\end{array}\right\}<\begin{array}{lll}1 & 1 & 1\end{array}\right\rangle_{\beta}$ twinning remationship.

\section{Conclusions}

The present investigation employed a single crystal with a nominal chemical composition of Ti-24Nb-4Zr-8Sn (wt. \%) to investigate the $\omega$ phase on the twin boundaries. Techniques including cyclic tensile test, in situ synchrotron X-ray diffraction, TEM observations and crystallographic orientation reconstruction are used to comprehensively analyze the deformation features. Results as following are obtained:

(1) The $\langle 110\rangle_{\beta}$ Ti2448 single crystal exhibits a maximum recoverable strain of $4.2 \%$ at the applied strain of $4.5 \%$. Incipient young's modulus and ultimate tensile strength were measured to be $51 \mathrm{GPa}$ and $623 \mathrm{MPa}$. SXRD profiles confirmed the superelasticity is due to phase transformation and cell parameters were thus obtained. 
(2) Surprisingly, apparition of diffracted peaks related to the $\omega$ phase is found on SXRD profiles when the stress is removed, only from the plastic deformation range. These peaks disappear after further loading and appear back after subsequent unloading. The $\left\{\begin{array}{lll}1 & 1 & 2\end{array}\right\}<1 \quad 1$ $1>_{\beta}$ deformation twinning is identified with diffraction patterns and TEM dark field images.

(3) Taking the sample deformed up to $4.5 \%$ as an example, the applied strain is accommodated by martensitic $\alpha$ " phase transformation strain (4.29\%) and plastic deformation leading to residual strain after unloading $(0.2 \%)$. The TEM analysis also shown the presence of ITB- $\omega$ phase located along twin boundaries. Accordingly to SXRD results, this ITB- $\omega$ phase is formed when the stress is released.

(4) From crystallographic reconstruction based on the orientation relationship, results illustrate that the observed $\left\{\begin{array}{lll}1 & 1 & 2\end{array}\right\}<1 \begin{array}{lll}1 & 1\end{array}>_{\beta}$ and ITB- $\omega$ phase are the resultant lattice complexion due to the reversion of $\left\{\begin{array}{llllll}1 & 1 & 0\end{array}\right\}\left\langle\begin{array}{llll}1 & 1 & 0\end{array}\right\rangle_{\alpha}$, twins. The ITB- $\omega$ phase formed is due to the compression strains during the reversed martensitic transformation on the twinning boundaries.

(5) The sequence of deformation can thus be described as follow:

(1) during loading, the $\beta$ phase firstly transforms into $\alpha^{\prime \prime}$ martensite; (2) when this transformation is fully accomplished, $\left\{\begin{array}{lllllll}1 & 1 & 0\end{array}\right\}<\begin{array}{lll}1 & 0 & \alpha^{\prime \prime}\end{array}$ twins are formed in the $\alpha "$ martensite during subsequent plastic deformation, as well as dislocation slip occurs; (3) when the stress is removed from the plastic deformation range, the reverse transformation from $\alpha^{\prime \prime}$ to $\beta$ phase occurs; (4) the twins formed into $\alpha^{\prime \prime}$ martensite reverse thus into a deformation band exhibiting a $\left\{\begin{array}{lllllll}1 & 1 & 2\end{array}\right\}<1 \quad 1 \quad 1>_{\beta}$ twinning relationship; (5) a thin layer of $\omega$ phase lying along the twin boundary (ITB $\omega$ phase) is also formed in order to relax the stress accompanying this reverse transformation.

\section{Acknowledgments}

The authors acknowledge the European Synchrotron Radiation Facility for provision of synchrotron radiation facilities and would like to thank Yves Watier for assistance in using the beamline ID31. The authors also acknowledge Prof. Yulin Hao and Dr. Haoliang Wang in Institute of Metal Research Chinese Academy of Sciences for providing single crystal, and Dr. Guanglong $\mathrm{Xu}$ for the helpful discussion on the theory of phase transformation. This work was supported by Shenzhen Fundamental Research (JCYJ 20160427170611414). 
[1] J.A. Klostermann, The concept of the habit plane and the phenomenological theories of the martensite transformation, Journal of the Less Common Metals 28(1) (1972) 75-94.

[2] D.S. Lieberman, M.S. Wechsler, T.A. Read, Cubic to Orthorhombic Diffusionless Phase ChangeExperimental and Theoretical Studies of AuCd, Journal of Applied Physics 26(4) (1955) 473-484.

[3] W. Sinkler, D. Luzzi, An electron diffraction investigation of the diffuse $\omega$ structure in quenched Ti-3d transition metal alloys, Acta Metallurgica et Materialia 42 (1994) 1249-1260.

[4] P.D. Frost, W.M. Parris, D.L. Hirsh, J.R. Diog, C.M. Schwattz, Isothermal transformation of titanium-chromium alloys, Transactions of the American Society for Metals 46 (1954) 231-256.

[5] T. Yamamoto, K. Hayashi, N. Happo, S. Hosokawa, H. Tajiri, Local atomic structure near an Nb atom in aged $\beta$-Ti alloys, Acta Materialia 131 (2017) 534-542.

[6] S. Shin, C. Zhang, K.S. Vecchio, Phase stability dependence of deformation mode correlated mechanical properties and elastic properties in Ti-Nb gum metal, Materials Science and Engineering: A 702 (2017) 173-183.

[7] L.M. Hsiung, D.H. Lassila, Shock-induced deformation twinning and omega transformation in tantalum and tantalum-tungsten alloys, Acta Materialia 48 (2000) 4851-4865.

[8] G.K. Dey, R. Tewari, S. Banerjee, G. Jyoti, S.C. Gupta, K.D. Joshi, S.K. Sikka, Formation of a shock deformation induced $\omega$ phase in Zr 20 Nb alloy, Acta Materialia 52(18) (2004) 5243-5254.

[9] L.M. Hsiung, D.H. Lassila, Shock-induced displacive transformations in Tantalum and Tantalum-Tungsten alloys, Acta Metallurgica 39 (1998) 603-609.

[10] A. Devaraj, S. Nag, R. Srinivasan, R.E.A. Williams, S. Banerjee, R. Banerjee, H.L. Fraser, Experimental evidence of concurrent compositional and structural instabilities leading to $\omega$ precipitation in titaniummolybdenum alloys, Acta Materialia 60(2) (2012) 596-609.

[11] D. Choudhuri, Y. Zheng, T. Alam, R. Shi, M. Hendrickson, S. Banerjee, Y. Wang, S.G. Srinivasan, H. Fraser, R. Banerjee, Coupled experimental and computational investigation of omega phase evolution in a high misfit titanium-vanadium alloy, Acta Materialia 130 (2017) 215-228.

[12] S.A. Mantri, D. Choudhuri, T. Alam, V. Ageh, F. Sun, F. Prima, R. Banerjee, Change in the deformation mode resulting from beta-omega compositional partitioning in a TiMo alloy: Room versus elevated temperature, Scripta Materialia 130 (2017) 69-73.

[13] H. Liu, M. Niinomi, M. Nakai, K. Cho, Athermal and deformation-induced $\omega$-phase transformations in biomedical beta-type alloy Ti-9Cr-0.2O, Acta Materialia 106 (2016) 162-170.

[14] H. Liu, M. Niinomi, M. Nakai, K. Cho, H. Fujii, Deformation-induced $\omega$-phase transformation in a $\beta$-type titanium alloy during tensile deformation, Scripta Materialia 130 (2017) 27-31.

[15] M. Tane, T. Nakano, S. Kuramoto, M. Niinomi, N. Takesue, H. Nakajima, $\omega$ Transformation in cold-worked $\mathrm{Ti}-\mathrm{Nb}-\mathrm{Ta}-\mathrm{Zr}-\mathrm{O}$ alloys with low body-centered cubic phase stability and its correlation with their elastic properties, Acta Materialia 61(1) (2013) 139-150.

[16] J. Zhang, C.C. Tasan, M.J. Lai, A.C. Dippel, D. Raabe, Complexion-mediated martensitic phase transformation in Titanium, Nature Communication 8 (2017) 14210.

[17] M. Niinomi, M. Nakai, M. Hendrickson, P. Nandwana, T. Alam, D. Choudhuri, R. Banerjee, Influence of 
oxygen on omega phase stability in the Ti-29Nb-13Ta-4.6Zr alloy, Scripta Materialia 123 (2016) 144-148.

[18] P. Castany, Y. Yang, E. Bertrand, T. Gloriant, Reversion of a Parent $\{130\}<310>$ alpha" Martensitic Twinning System at the Origin of $\{332\}<113>$ beta Twins Observed in Metastable beta Titanium Alloys, Physical Review Letters 117(24) (2016) 245501.

[19] M.J. Lai, C.C. Tasan, J. Zhang, B. Grabowski, L.F. Huang, D. Raabe, Origin of shear induced $\beta$ to $\omega$ transition in Ti-Nb-based alloys, Acta Materialia 92 (2015) 55-63.

[20] B. Horovitz, J.L. Murray, J.A. Krumhansl, Stacking solitons in $\omega$-phase systems and quasielastic scattering, Physical Review B 18(7) (1978) 3549-3558.

[21] H. Xing, J. Sun, Mechanical twinning and omega transition by $<111>\{112\}$ shear in a metastable $\beta$ titanium alloy, Applied Physics Letters 93(3) (2008) 031908.

[22] Y. Yang, G.P. Li, H. Wang, S.Q. Wu, L.C. Zhang, Y.L. Li, K. Yang, Formation of zigzag-shaped $\{112\}<111>$ b mechanical twins in Ti-24.5 Nb-0.7 Ta-2 Zr-1.4 O alloy, Scripta Materialia 66(5) (2012) 211-214.

[23] L. Li, W. Mei, H. Xing, X.L. Wang, J. Sun, Zigzag configuration of mechanical twin and stress-induced omega phase in metastable $\beta$ Ti-34Nb (at.\%) alloy, Journal of Alloys and Compounds 625 (2015) 188-192.

[24] S.Q. Wu, D.H. Ping, Y. Yamabe-Mitarai, W.L. Xiao, Y. Yang, Q.M. Hu, G.P. Li, R. Yang, \{112\}<111> Twinning during $\omega$ to body-centered cubic transition, Acta Materialia 62 (2014) 122-128.

[25] Y.L. Hao, Z.B. Zhang, S.J. Li, R. Yang, Microstructure and mechanical behavior of a Ti-24Nb-4Zr-8Sn alloy processed by warm swaging and warm rolling, Acta Materialia 60(5) (2012) 2169-2177.

[26] H. Zhan, G. Wang, D. Kent, M. Dargusch, The dynamic response of a metastable $\beta$ Ti-Nb alloy to high strain rates at room and elevated temperatures, Acta Materialia 105 (2016) 104-113.

[27] X.L. Wang, L. Li, H. Xing, P. Ou, J. Sun, Role of oxygen in stress-induced $\omega$ phase transformation and $\{332\}<113>$ mechanical twinning in $\beta$ Ti-20V alloy, Scripta Materialia 96 (2015) 37-40.

[28] Y.Yang, P. Castany, E. Bertrand, M. Cornen, T. Gloriant, Investigation of mechanical twinning ijn the Ti-24Nb-4Zr-8Sn b titanium alloy, Proceedings of the 13th World Conference on Titanium (2016) 1783-1786.

[29] O.Izumi, S. Hanada, Transmission electron microscopic observations of mechanical twinning in metastable beta titanium alloys, Metalllurgical Transactions A 17 (1986) 1409-1420.

[30] E. Bertrand, P. Castany, I. Péron, T. Gloriant, Twinning system selection in a metastable $\beta$-titanium alloy by Schmid factor analysis, Scripta Materialia 64(12) (2011) 1110-1113.

[31] A. Ramarolahy, P. Castany, F. Prima, P. Laheurte, I. Peron, T. Gloriant, Microstructure and mechanical behavior of superelastic Ti-24Nb-0.5O and Ti-24Nb-0.5N biomedical alloys, Journal of the Mechanical Behavior of Biomedical Materials 9 (2012) 83-90.

[32] E. Sukedai, M. Shimoda, H. Nishizawa, Y. Nako, Nucleation Behaviour of beta to omega Phase Transformations in beta-Type Ti-Mo Alloys, Materials Transactions 52(3) (2011) 324-330.

[33] D.H. Ping, Review on $\omega$ Phase in Body-Centered Cubic Metals and Alloys, Acta Metallurgica Sinica (English Letters) 27(1) (2014) 1-11.

[34] L.C. Zhang, D. Klemm, J. Eckert, Y.L. Hao, T.B. Sercombe, Manufacture by selective laser melting and mechanical behavior of a biomedical Ti-24Nb-4Zr-8Sn alloy, Scripta Materialia 65(1) (2011) 21-24.

[35] Y. Yang, P. Castany, M. Cornen, I. Thibon, F. Prima, T. Gloriant, Texture investigation of the superelastic Ti24Nb-4Zr-8Sn alloy, Journal of Alloys and Compounds 591 (2014) 85-90.

[36] Y.J. Liu, X.P. Li, L.C. Zhang, T.B. Sercombe, Processing and properties of topologically optimised 
biomedical Ti-24Nb-4Zr-8Sn scaffolds manufactured by selective laser melting, Materials Science and Engineering: A 642 (2015) 268-278.

[37] Y. Yang, P. Castany, M. Cornen, F. Prima, S.J. Li, Y.L. Hao, T. Gloriant, Characterization of the martensitic transformation in the superelastic $\mathrm{Ti}-24 \mathrm{Nb}-4 \mathrm{Zr}-8 \mathrm{Sn}$ alloy by in situ synchrotron $\mathrm{X}$-ray diffraction and dynamic mechanical analysis, Acta Materialia 88 (2015) 25-33.

[38] H.L. Wang, Y.L. Hao, S.Y. He, K. Du, T. Li, E.G. Obbard, J. Hudspeth, J.G. Wang, Y.D. Wang, Y. Wang, F. Prima, N. Lu, M.J. Kim, J.M. Cairney, S.J. Li, R. Yang, Tracing the coupled atomic shear and shuffle for a cubic to a hexagonal crystal transition, Scripta Materialia 133 (2017) 70-74.

[39] H.L. Wang, Y.L. Hao, S.Y. He, T. Li, J.M. Cairney, Y.D. Wang, Y. Wang, E.G. Obbard, F. Prima, K. Du, S.J. Li, R. Yang, Elastically confined martensitic transformation at the nano-scale in a multifunctional titanium alloy, Acta Materialia 135 (2017) 330-339.

[40] P. Castany, A. Ramarolahy, F. Prima, P. Laheurte, C. Curfs, T. Gloriant, In situ synchrotron X-ray diffraction study of the martensitic transformation in superelastic Ti-24Nb-0.5N and Ti-24Nb-0.5O alloys, Acta Materialia 88 (2015) 102-111.

[41] T. Grosdidier, M.J. Philippe, Deformation induced martensite and superelasticity in a b-metastable titanium alloy, Materials Science and Engineering A 291 (2000) 218-223.

[42] P. Castany, D.M. Gordin, S.I. Drob, C. Vasilescu, V. Mitran, A. Cimpean, T. Gloriant, Deformation Mechanisms and Biocompatibility of the Superelastic Ti-23Nb-0.7Ta-2Zr-0.5N Alloy, Shape Memory and Superelasticity 2(1) (2016) 18-28.

[43] G. Taylor, Thermally-activated deformation of BCC metals and alloys, Progress in Materials Science 36 (1992) 29-61.

[44] P. Castany, M. Besse, T. Gloriant, In situ TEM study of dislocation slip in a metastable $\beta$ titanium alloy, Scripta Materialia 66(6) (2012) 371-373.

[45] P. Castany, M. Besse, T. Gloriant, Dislocation mobility in gum metal $\beta$-titanium alloy studied viain situtransmission electron microscopy, Physical Review B 84(2) (2011).

[46] H. Tobe, H.Y. Kim, T. Inamura, H. Hosoda, S. Miyazaki, Origin of $\{332\}$ twinning in metastable $\beta$-Ti alloys, Acta Materialia 64 (2014) 345-355.

[47] E. Bertrand, P. Castany, Y. Yang, E. Menou, T. Gloriant, Deformation twinning in the full- $\alpha^{\prime \prime}$ martensitic Ti25Ta-20Nb shape memory alloy, Acta Materialia 105 (2016) 94-103.

[48] D.H. Ping, Y. Yamabe-Mitarai, C.Y. Cui, F.X. Yin, M.A. Choudhry, Stress-induced $\alpha^{\prime \prime}$ martensitic (110) twinning in $\beta$-Ti alloys, Applied Physics Letters 93(15) (2008) 151911.

[49] Y.W. Chai, H.Y. Kim, H. Hosoda, S. Miyazaki, Self-accommodation in Ti-Nb shape memory alloys, Acta Materialia 57(14) (2009) 4054-4064.

[50] R.W. Cahn, Plastic deformation of alpha-uranium twinning and slip, Acta Metallurgica 1 (1953) 49-70.

[51] A.G. Crocker, The crystallography of deformation twinning in alpha-uranium, Journal of Nuclear Materials 16 (1965) 306-326.

[52] R.D. Field, R.J. McCabe, D.J. Alexander, D.F. Teter, Deformation twinning and twinning related fracture in coarse-grained $\alpha$-uranium, Journal of Nuclear Materials 392(1) (2009) 105-113.

[53] T. Inamura, J.I. Kim, H.Y. Kim, H. Hosoda, K. Wakashima, S. Miyazaki, Composition dependent crystallography of $\alpha^{\prime \prime}$-martensite in Ti-Nb-based $\beta$-titanium alloy, Philosophical Magazine 87(23) (2007) 
498

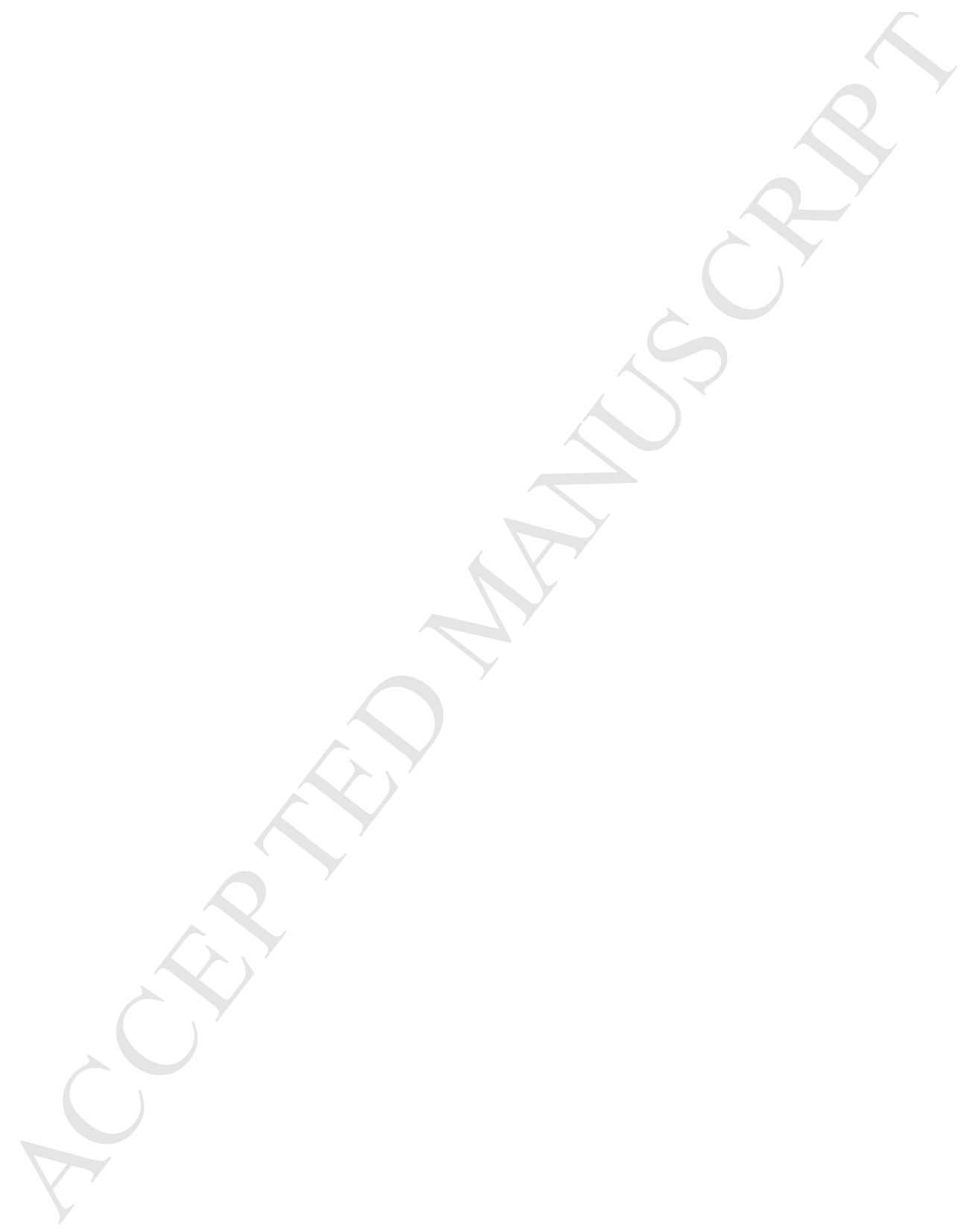


Table 1. Cell parameters of different phases after releasing stress at higher applied strain in the plastic deformation range.

\begin{tabular}{|c|c|c|c|c|c|c|}
\hline \multirow{3}{*}{ Cell parameters $(\AA ̊ \AA)$} & \multirow{2}{*}{\multicolumn{2}{|c|}{$\begin{array}{c}\text { loading } \\
\text { SIM } \alpha^{\prime \prime} \text { phase }\end{array}$}} & \multicolumn{4}{|c|}{ Unloading } \\
\hline & & & \multicolumn{2}{|c|}{$\beta$ phase } & \multicolumn{2}{|c|}{$\omega$ phase } \\
\hline & $4.5 \%$ & $5.5 \%$ & $4.5 \%$ & $5.5 \%$ & $4.5 \%$ & $5.5 \%$ \\
\hline $\mathrm{a}$ & 3.261 & 3.260 & \multirow{3}{*}{3.298} & \multirow{3}{*}{3.298} & 4.732 & 4.732 \\
\hline $\mathrm{b}$ & 4.864 & 4.865 & & & 4.732 & 4.732 \\
\hline $\mathrm{c}$ & 4.848 & 4.851 & & & 2.991 & 2.991 \\
\hline
\end{tabular}

Table 2. The six lattice correspondence of variants for martensitic $\alpha$ " phase derived from the parent $\beta$ phase and the calculated strain of phase transformation at the external loading direction of $\left[\begin{array}{lll}1 & 0 & 1\end{array}\right]_{\beta}$.

\begin{tabular}{|c|c|c|c|c|c|}
\hline \multirow{2}{*}{$\begin{array}{c}\text { Variants } \\
\text { correspondence }\end{array}$} & {$[\mathbf{1 0 0}]_{\boldsymbol{\alpha}^{\prime \prime}}$} & {$[\mathbf{0 1 0}]_{\boldsymbol{\alpha}}$} & & {$[\mathbf{0 0 1}]_{\boldsymbol{\alpha}}$} & \multicolumn{2}{|c|}{$\begin{array}{c}\text { Transformation strain along the } \\
\text { loading direction of [101] }\end{array}$} \\
\cline { 3 - 6 } & & & & $\begin{array}{c}\text { Applied strain } \\
\text { of 4.5\% }\end{array}$ & $\begin{array}{c}\text { Applied strain of } \\
\mathbf{5 . 5 \%}\end{array}$ \\
\hline $\mathrm{CV} 1$ & {$[100]_{\beta}$} & {$[011]_{\beta}$} & {$[0 \overline{1} 1]_{\beta}$} & 1.50 & 1.50 \\
\hline $\mathrm{CV} 2$ & {$[100]_{\beta}$} & {$[0 \overline{1} 1]_{\beta}$} & {$[0 \overline{1} \overline{1}]_{\beta}$} & 1.50 & 1.50 \\
\hline $\mathrm{CV} 3$ & {$[\mathbf{0 1 0}]_{\beta}$} & {$[\mathbf{1 0 1}]_{\beta}$} & {$[\mathbf{1 0} \overline{1}]_{\beta}$} & 4.29 & 4.31 \\
\hline $\mathrm{CV} 4$ & {$[010]_{\beta}$} & {$[10 \overline{1}]_{\beta}$} & {$[\overline{1} 0 \overline{1}]_{\beta}$} & 3.94 & 4.01 \\
\hline $\mathrm{CV} 5$ & {$[001]_{\beta}$} & {$[110]_{\beta}$} & {$[\overline{1} 10]_{\beta}$} & 1.50 & 1.50 \\
\hline $\mathrm{CV} 6$ & {$[001]_{\beta}$} & {$[\overline{1} 10]_{\beta}$} & {$[\overline{1} \overline{1} 0]_{\beta}$} & 1.50 & 1.50 \\
\hline
\end{tabular}




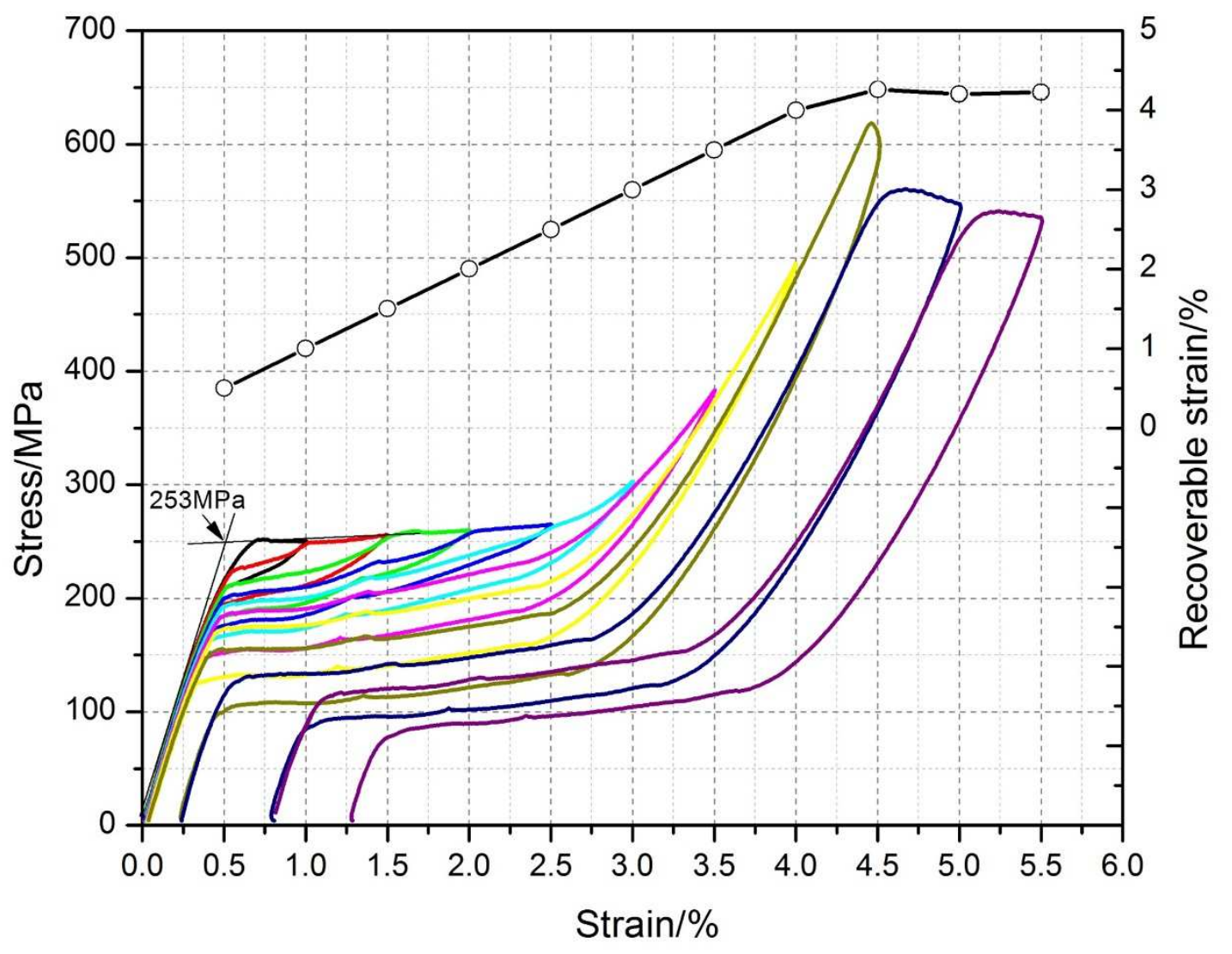

Fig. 1. Cyclic tensile curve of the single crystal Ti-24Nb-4Zr-8Sn alloy with the corresponding measured recoverable strains (open circles). 

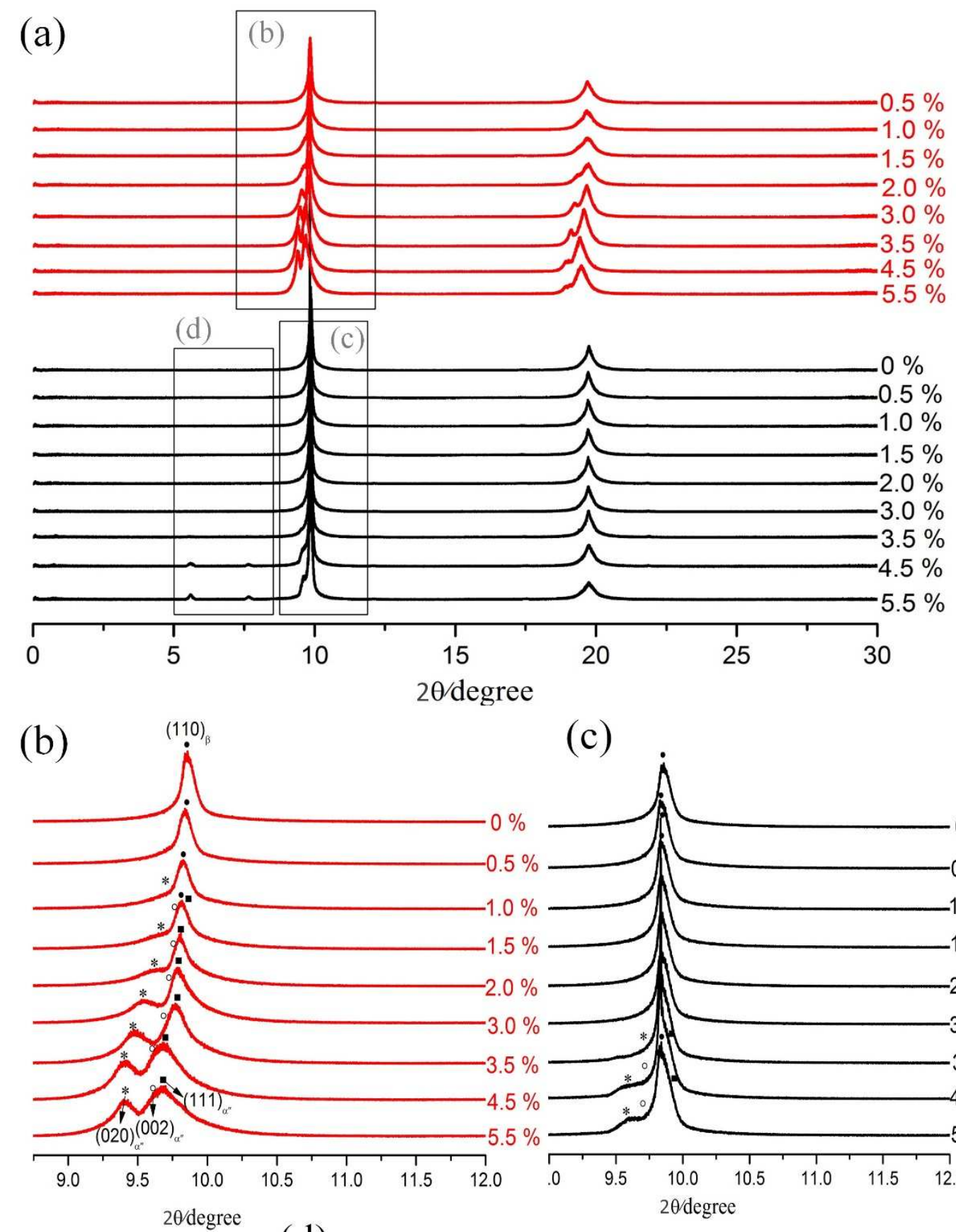

(c)

(d)
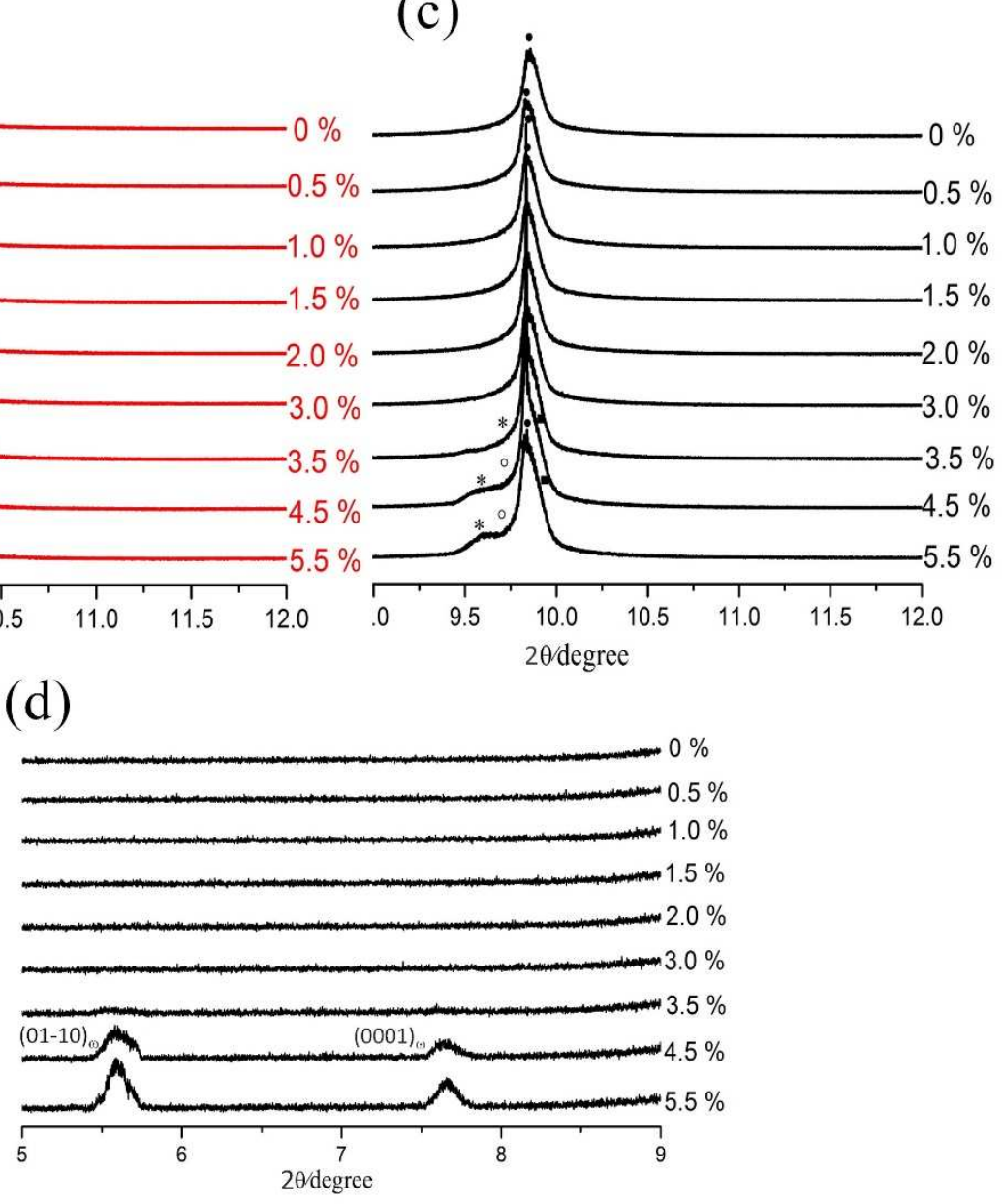

Fig. 2. Synchrotron X-ray diffraction profiles of the single crystal Ti-24Nb-4Zr-8Sn alloy: (a) the full diffractograms on loading and corresponding unloading and (b-d) enlarged partial diffractograms marked in (a) with precise indexation. 


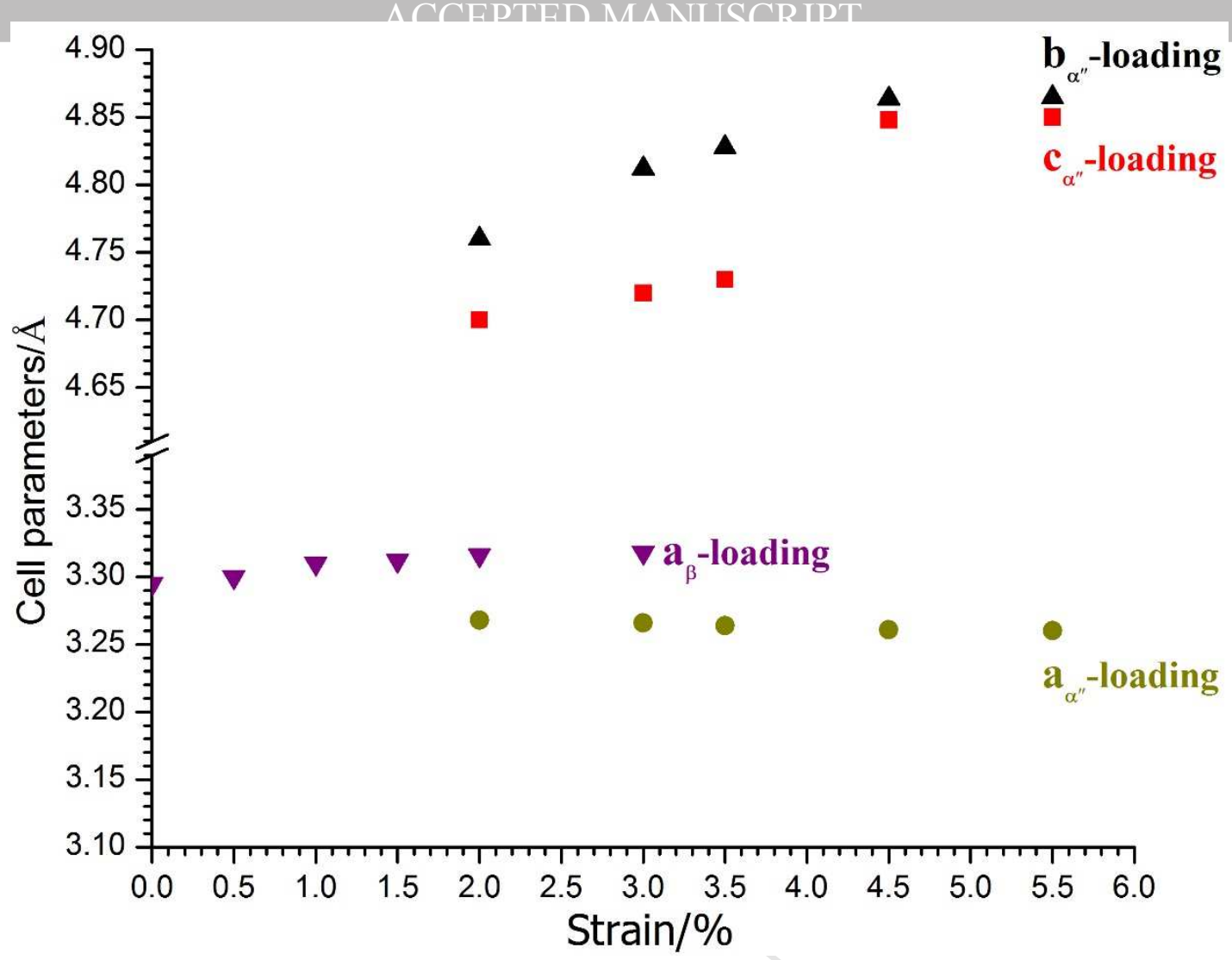

Fig. 3. Evolution of the cell parameters of the different phases determined from the SXRD profiles.

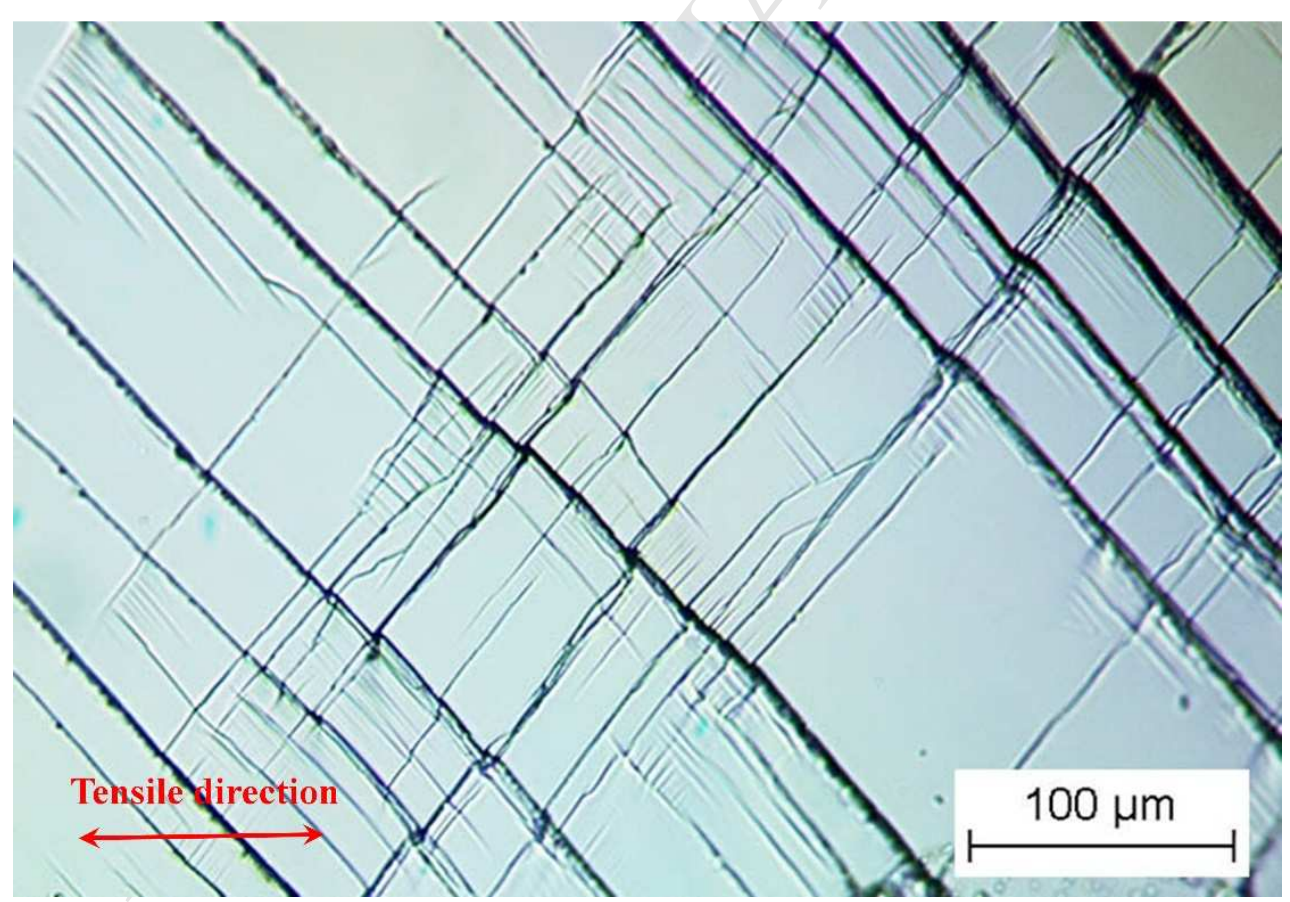

Fig. 4. Optical microstructure of the single crystal Ti-24Nb-4Zr-8Sn alloy after deformation up to $4.5 \%$ strain. 

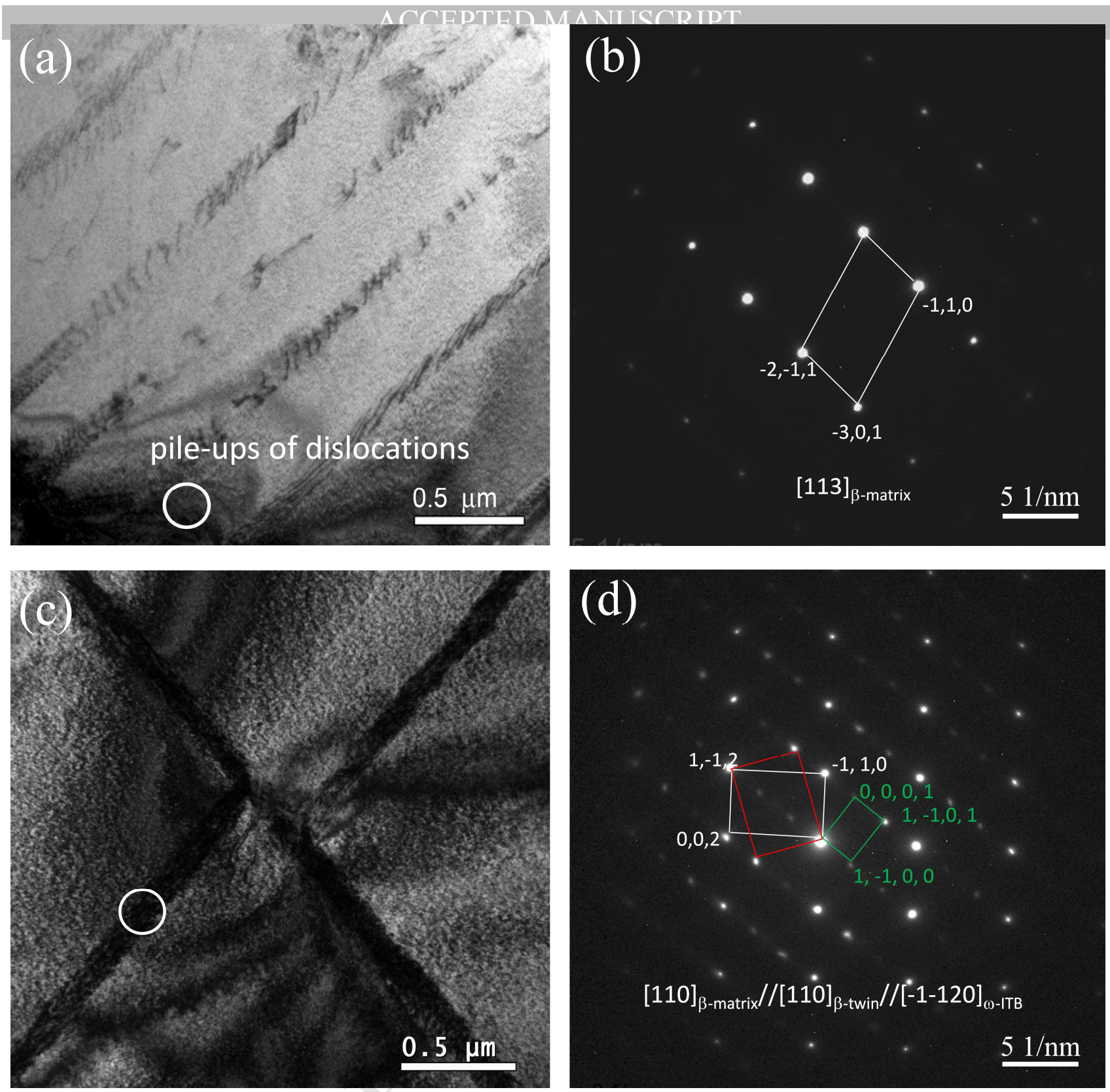

Fig. 5. TEM observations of the sample deformed up to $4.5 \%$ strain: (a) pile-ups of dislocations and (b) corresponding selected diffraction pattern of the area marked by white circle in (a); (c) two deformation bands crossing with each other and (d) the selected diffraction pattern of the area marked by white circle in (c). 

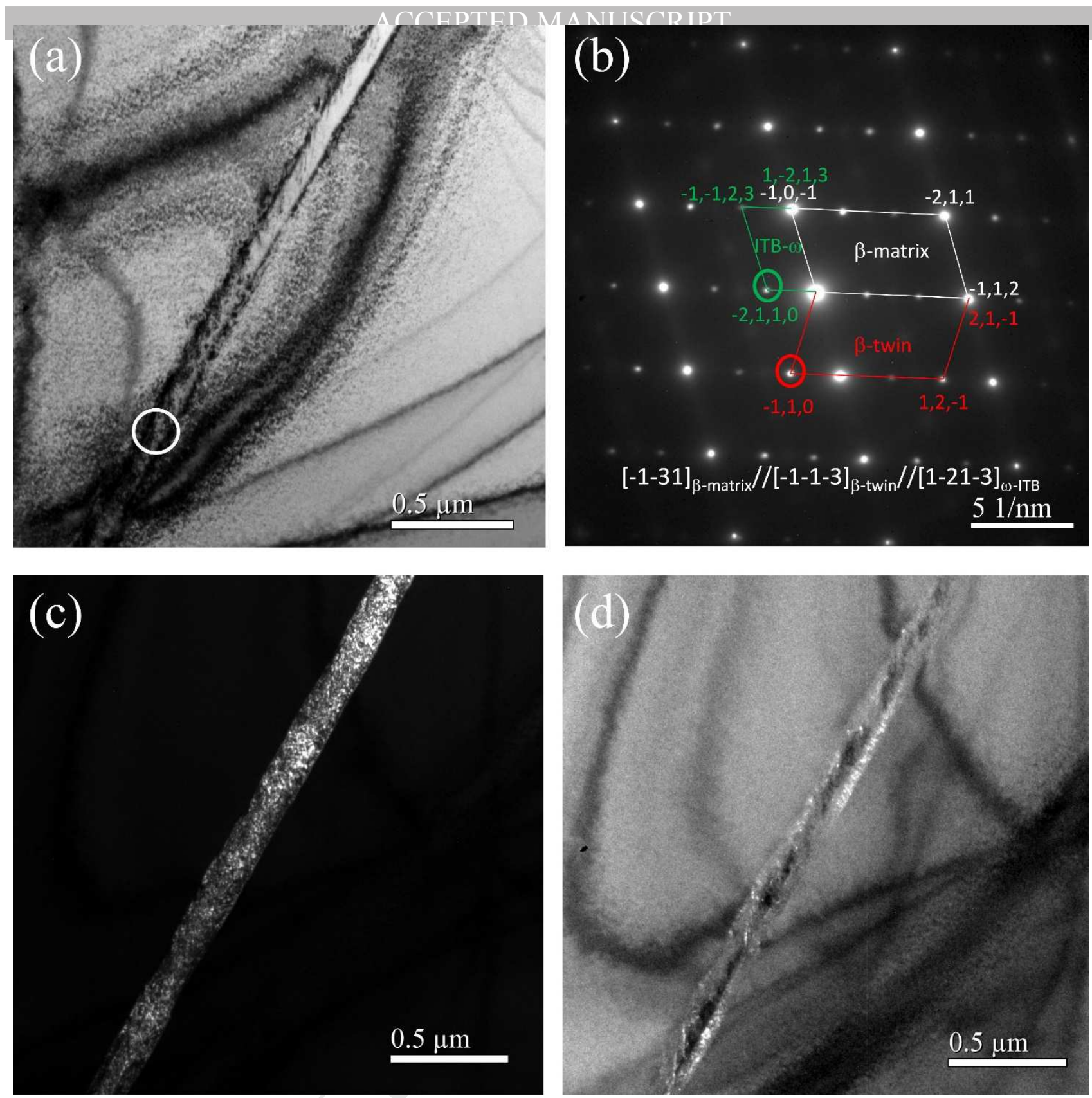

Fig. 6. TEM observations of one single deformation band for the sample deformed up to $4.5 \%$ strain: (a) bright field image and (b) the corresponding selected area diffraction patterns; (c) and (d) the dark field images taken with the spots highlighted by red and green circles in (c) corresponding to (-1 110$)_{\beta}$ and (-2 1110$)_{\omega}$, respectively. 
(a) $\beta$ - matrix

(b) $\beta$ - twin band

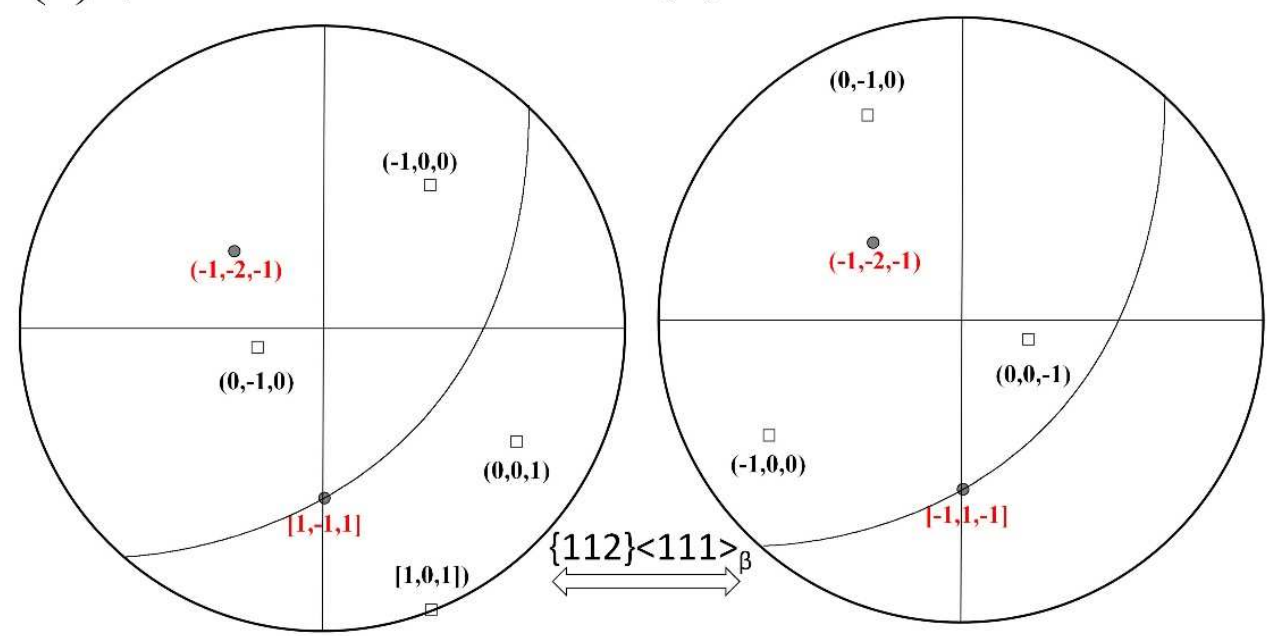

(c) $\alpha^{\prime \prime}-$ matrix - V3

(d) $\alpha^{\prime \prime}$ - twin band - V3

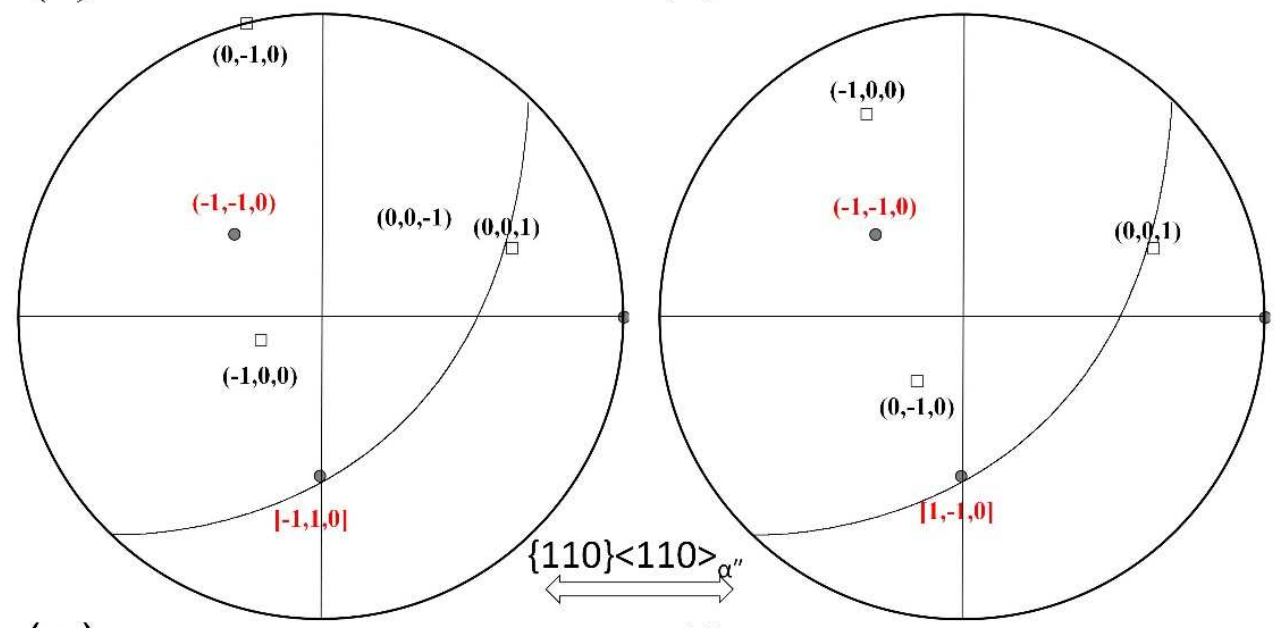

(e) ITB - $\omega$

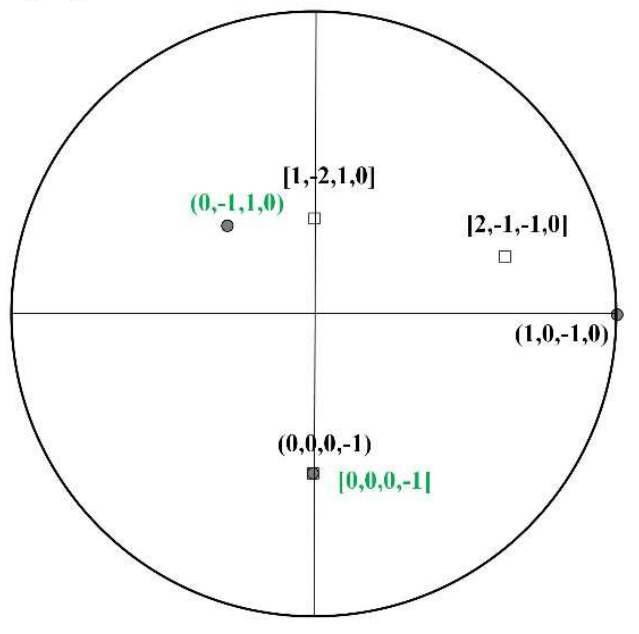

(f)

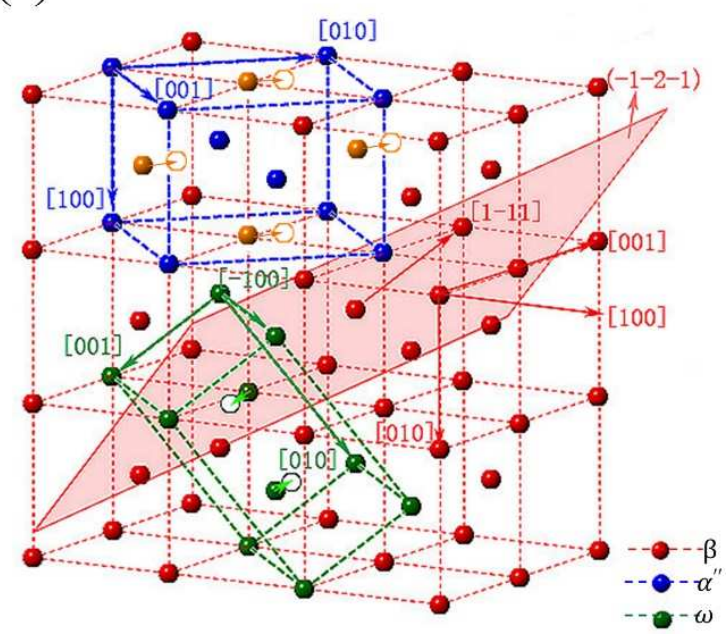

Fig. 7 Crystallographic orientations represented as stereographic projections used to determine the orientation relationship between the matrix and twin shown in Fig. 6: the (-1 -1 -2)[ $\left[\begin{array}{lll}1 & -1 & 1\end{array}\right]_{\beta}$ twinning relationship between the $\beta$-matrix (a) and the $\beta$-twin band (b); the compound (-1 $-1 \quad 0)\left[\begin{array}{lll}-1 & 1 & 0\end{array}\right]_{\alpha^{\prime \prime}}$ twinning relationship between the $\alpha$ "-matrix-V3 (c) and the $\alpha$ "-twin band-V3 (d); (e) the orientation of ITB- $\omega$ phase and (f) the lattice correspondence of $\beta$-matrix, $\alpha$ "-matrix-V3 and ITB- $\omega$ phase. 


\section{(a) loading}

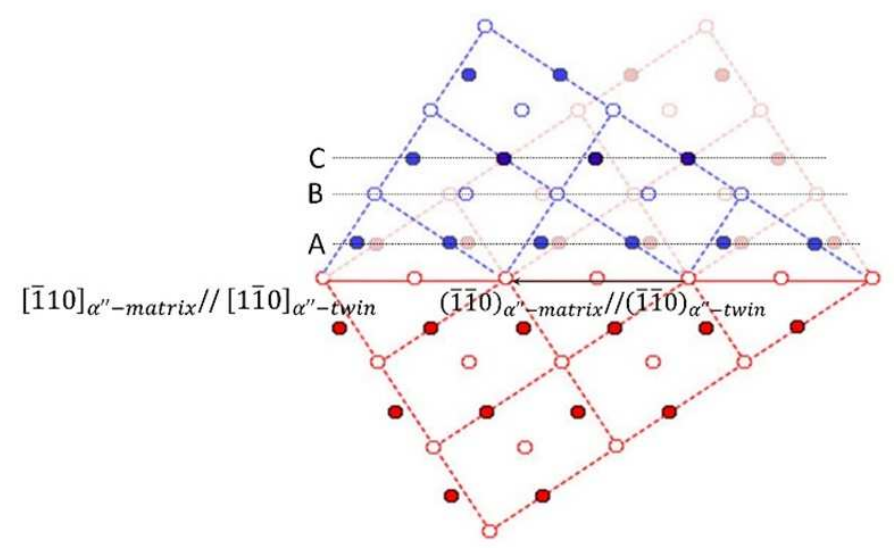

\section{(c) unloading}

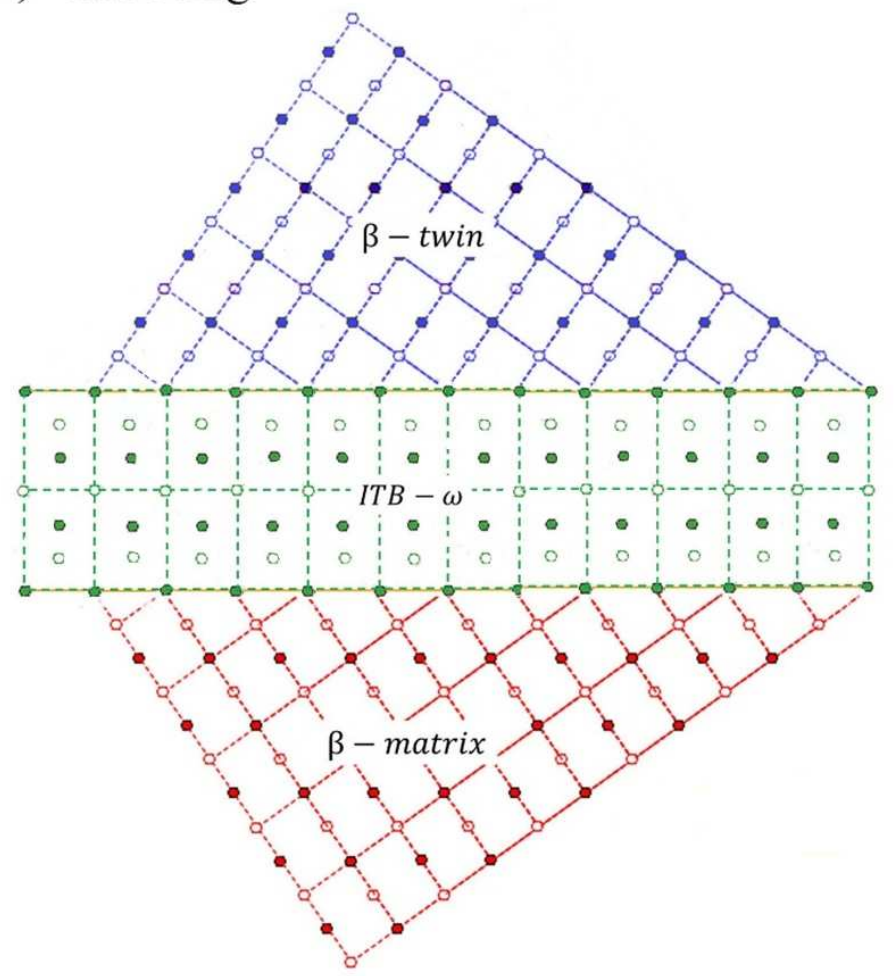

(b) unloading
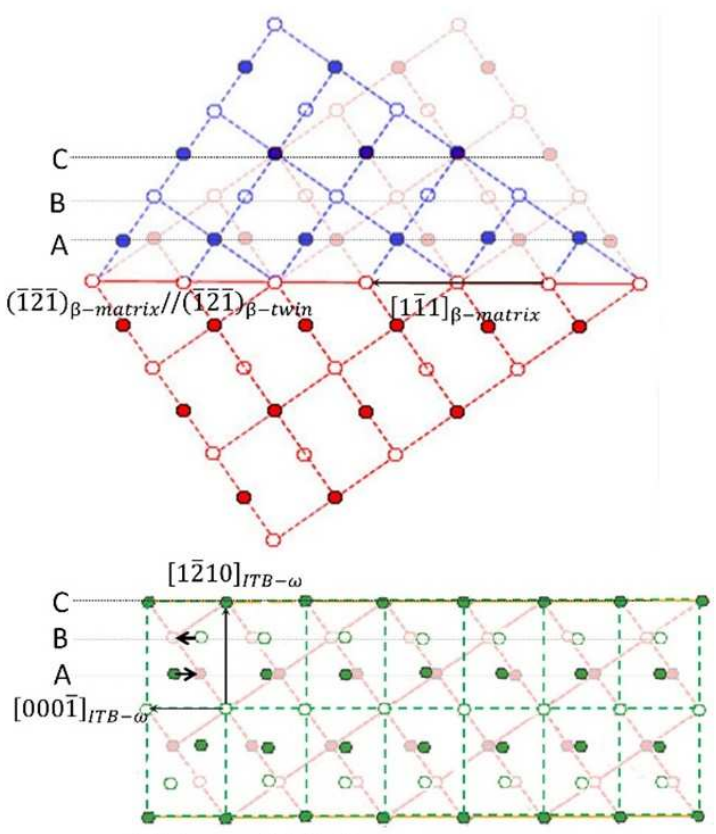

$(\overline{1} \overline{2} \overline{1})_{\beta-t w i n} / /(0 \overline{1} 10)_{I T B-\omega}$

Fig. 8 Schematic illustration of orientation relationships for single crystal Ti-24Nb-4Zr-8Sn alloy: (a) the compound $\left(\begin{array}{lll}-1 & -1 & 0\end{array}\right)\left[\begin{array}{lll}-1 & 1 & 0\end{array}\right]_{\alpha}$, twinning relationship on loading, (b) the $\left(\begin{array}{lll}-1 & -1 & -2\end{array}\right)\left[\begin{array}{lll}1 & -1 & 1\end{array}\right]_{\beta}$ twinning relationship and formation of ITB- $\omega$ after unloading and (c) the whole reversed morphology under unloading condition. 